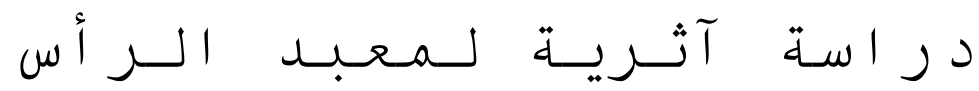

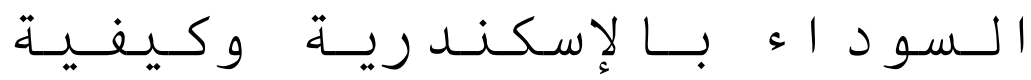

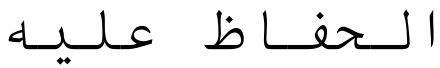

هـنــ جـلال يـوسف عـاقـول 
نقل المعابد بين القيمة الأثرية والتاريخية واستمرارية الحفاظ علي الآثر

(دراسة تطبيقية علي معبد الرأس السوداء بالإسكندرية)

حظيت الإسكندرية بإنشارات متعددة في كتابات المصادر الكلاسيكية والتي تتحدث عن رونق وجمال الإسكندرية في عصريها البطلمي والروماني, كما تتعددت هذه الإثشارات عن مبانيها المختلفة من الطرازين اليوناني والروماني سواء بالنسبة للمباني

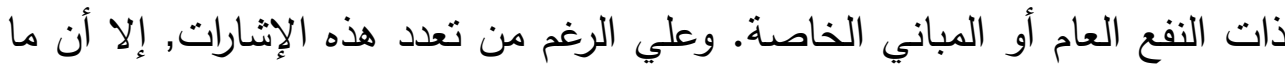

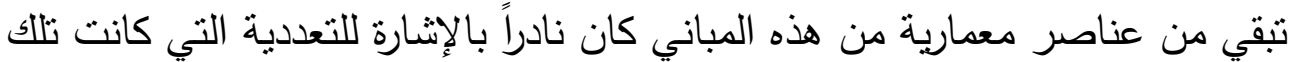
المباني تحظي بها في تلك العصور , يضاف لندرة ما تبقي من هذه المباني ندرة أيضاً

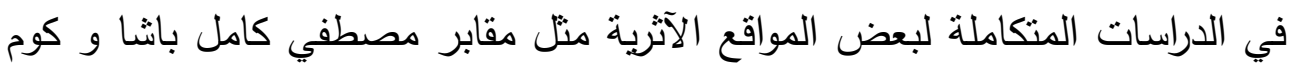

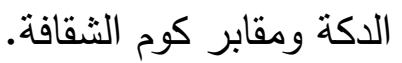

وتقع الإسكندية علي قطعة من اليابسة تكونت في الأزمنة الجيولوجية القديمة

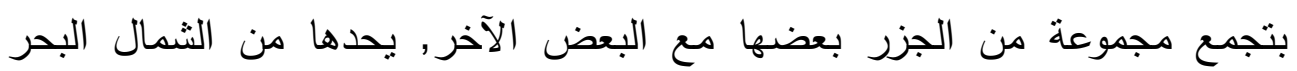

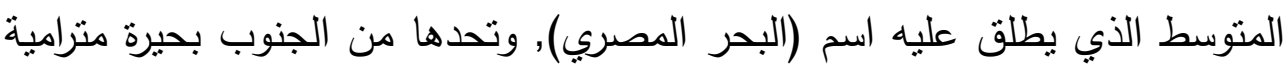

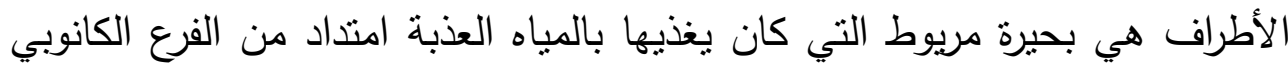
للنيل كان يصب في خليج الكانوب (أبو قير). اكتسب هذا الموقع أهمية كبيرة في العصور الفرعونية وخاصة في عصر العرب الدولة

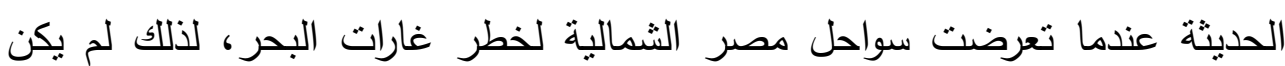

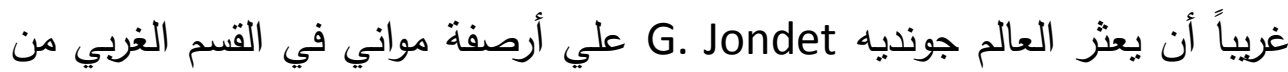
جزيرة تقع قبالة اليابس وتعرف بأسم جزيرة فاروس.

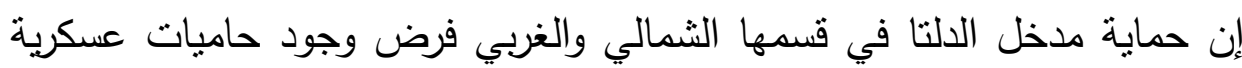

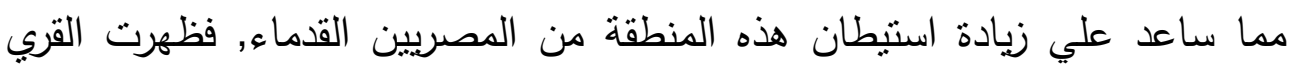

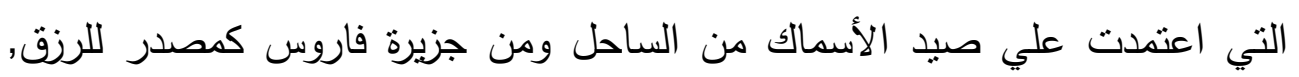


بالإضافة إلي توافر مياه عذبة ترد إليها من بحيرة مريوط فنشأ في العصر الفرعوني علي الساحل القاري ميناء يشبه صندوق عرف فيما بعد باسم 'Kibotos .

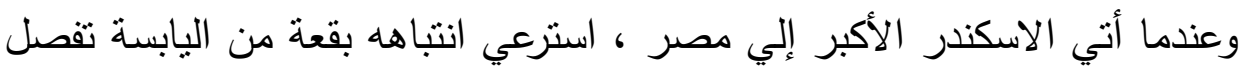

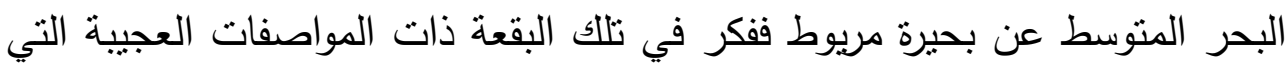

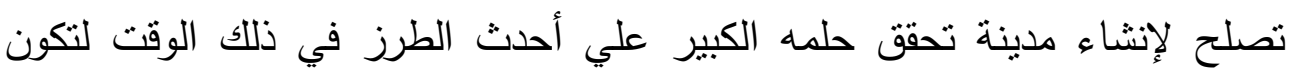
عاصمة عالمية و ذللك لأنها كانت تتميز بما يلي:

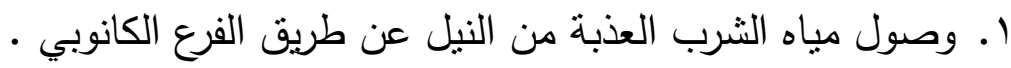

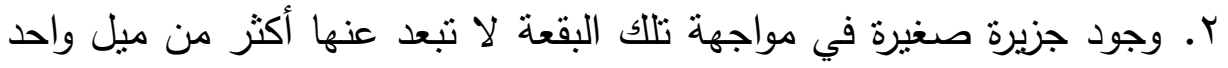
مما يمكن وصلهما معاً. r. تعتبر هذه الجزيرة جبهة دفاعية أمامية للمدينة . ع. وجود بحيرة مريوط جنوب هذه اليابسة يشكل تحصيناً دفاعياً من ناحية

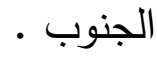

0. جفاف المنطقة, وبعد الموقع عن النأثر بطمي النيل حيث يتم طرده بواسطة

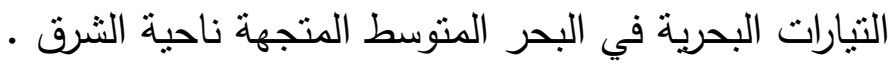

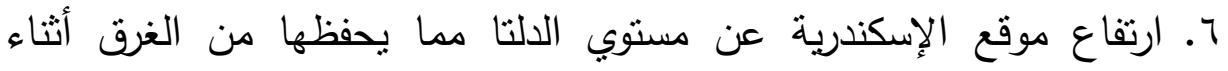

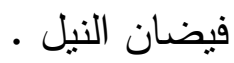
V. وجود قرية تسمي راكوتيوس (راقودة) التي كانت مأهولة بالسكان الذين بعلمون بالصيد , فتكون نواة للمدينة الجديدة .

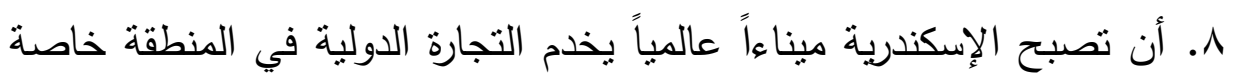

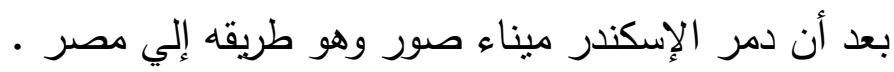

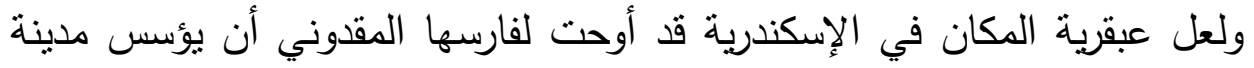

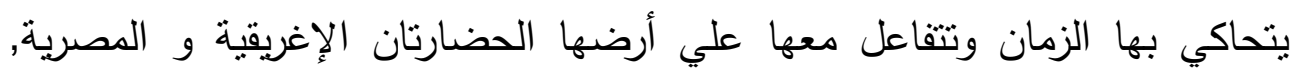


فأضفي الإسكندر بعبقريته الفذة إضافة إلي عبقرية المكان طرازاً متفرداً لهذه الددينة

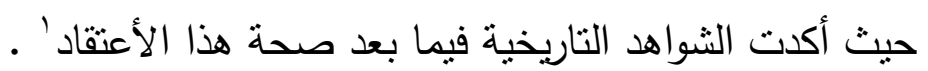
ومن هنا اختمرت الفكرة في ذهن الإسكندر وأراد تحقيقها علي وجه السرعة فعهد النا

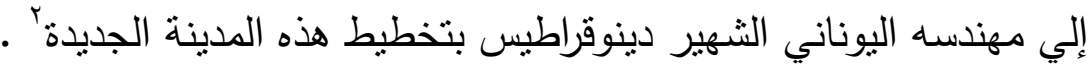

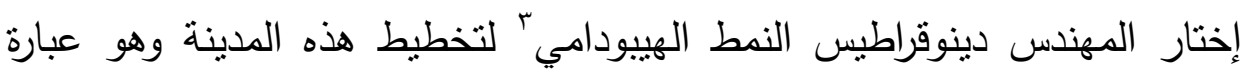
شارعين رئيسين متقاطعين بزاوية قائمة, ثم تخطيط شوارع أخري فرعية تتوازي مع كل

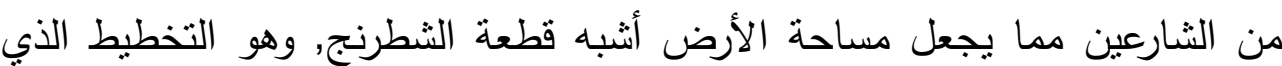

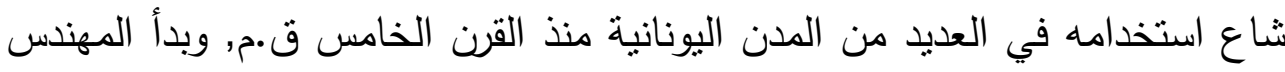
دينوقراطيس بمد جسر يربط بين الجزيرة وبين اليابسة, هذه الجزيرة هي التي سميت

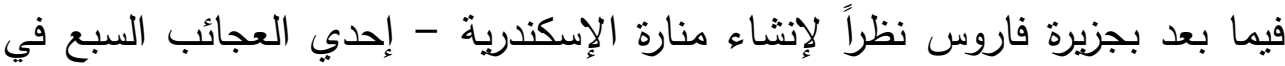
العالم القديم - علي الطرف الثرقي لها ـ وكان طول هذا الجسر يبلغ سبعة إستاديوم أي ما يقرب من · .. Tامتر مما جعله يكتسب اسم هيبتاستاديوم Heptastadium

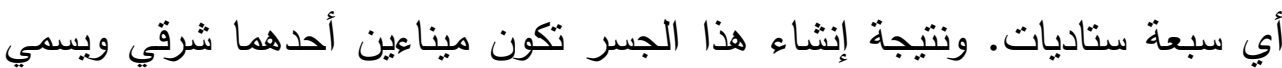
بالميناء الكبير Portus Magnus، والآخر غربي وسمي بميناء العود الحميد PortusEunostus, وكان الميناء الثرقي هو الميناء التجاري والأكثر أهمية في لهيكي العصرين اليوناني والروماني. ويحدثنا المؤرخ سترابون أنه في لحظة تأسيس مدينة الإسكندرية وعند تخطيطه لشوارع المدينة استخدمت كميات من الجير المناح في المنطقة ولكنه نفد قبل أن يتم تخطيط كل الثوارع لذا فقد استعان المهند دينوقراطيس بالقمح الخاص لطعام

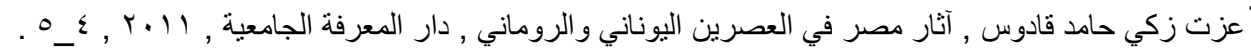
2Bernand , A. , Alexandrie la Grande , Arthaud , 1966 , p. 57

ז'التخطيط الهييودامي : هو نمط من تخطيط المدن علي شكل رقعة الثطرنج ابتدعه المهندس هيبوداموس

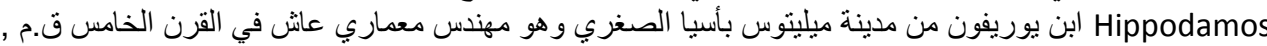

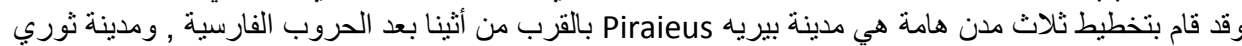
Thourioi

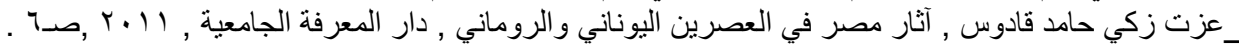
يوليو \& 1 ـ 
الجنود لتخطبط بقية الثوارع' .

وقد تحدث استرابون عن ملائمة الموقع الذي اختاره الإسكندر , فالمكان محفوف

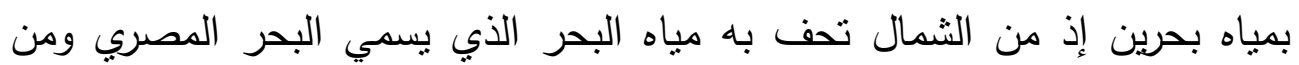

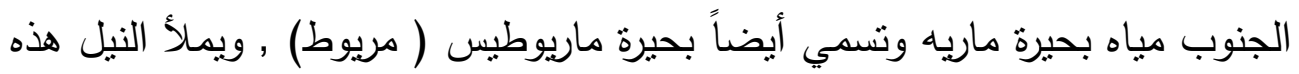
البحيرة بواسطة قنوات عديدة من أعلي و من الجوانب .

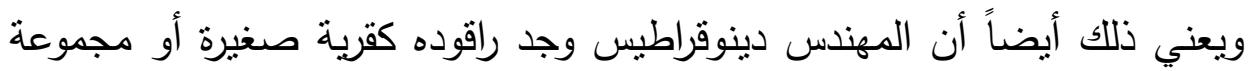

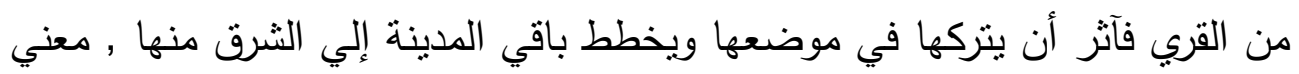

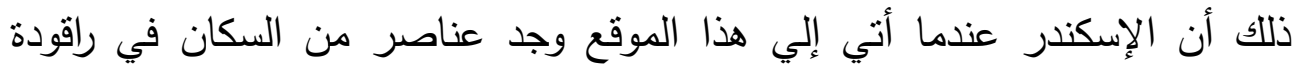

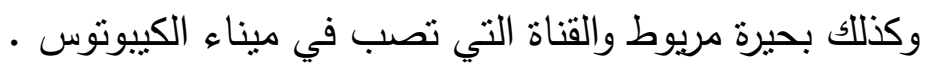

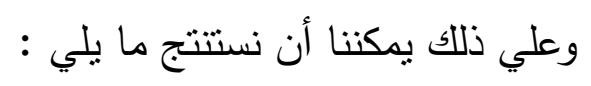
- - أن الإسكندرية القديمة قد أسست علي أساس المساحة الخالية أو الفراغ الذي تشغله قرية راقودة واستمرت راقوده كحي وطني للمصرين المقيمين قبل مجئ الإني

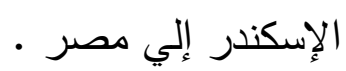
- أن الإسكندرية كانت تنشمل _ في تخطيطها الأصلي _ المباني الهامة

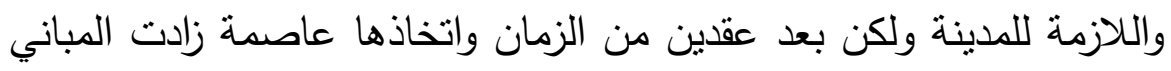

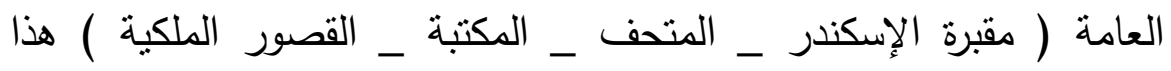

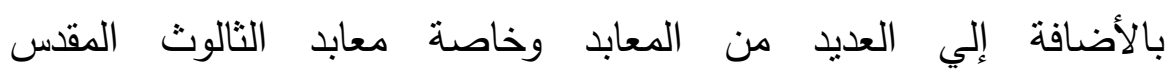
(سبرابيس_إيزيس_حربوقراط) .

هذا وقد أخذت مدينة الأسكندرية في الإتساع خاصة ناحية الثرق وذلك مع زيادة

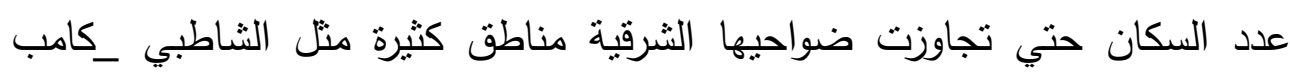
شيزار_الإبراهيمية_مصطفي كامل حتي كانوب (أبوقير) .

${ }^{1} \mathrm{~N}$. A. Mervit, Alexandria and others centers of Thought in Ancient Egypt, Alexandria, 2011, p. 60 .

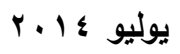




\section{تقسيم المدينة}

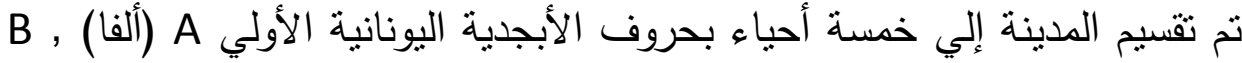

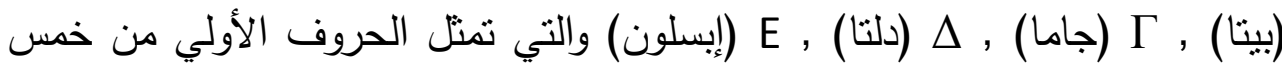
كلمات يونانية وترجمنها : " شيدها الإسكندر الملك ابن الإله " ـ وقد اعتمد تخطيط دينوقراطيس علي وجود شارعين رئيسين : حيث يمتد الثارع الرئيسي العرضي من الثرق إلي الغرب في وسط المدينة وهو معروف بشارع كانوب ( شارع فؤاد حالياً ) ويحده من الثرق بوابة الكانوب ومن الغرب باب سدرة ـ أما الثارع الطولي الذي لفي يمتد من الثمال إلي الجنوب فهو يقابل الآن شارع النبي دنبال وكان يحده من الثمال

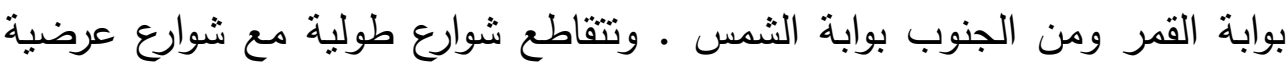

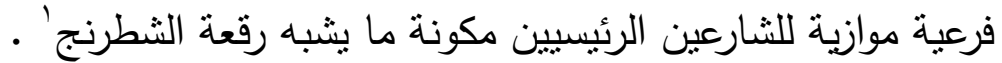

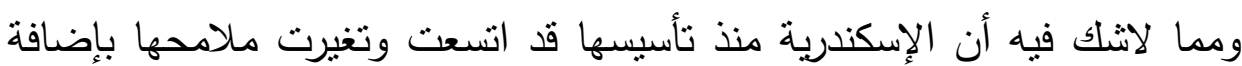
العديد من المباني التي تتسب في أغلبها إلي بطلميوس الأول (سوتير) وبطلميوس

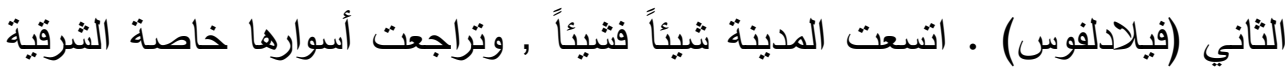
منها نظراً لإستحالة هذا الأتساع من الناحية الغربية لوجود مدينة الموتي Necropolis حتي العصر الروماني حيث وصلت أقصي إنساع لها في عصر الإمبراطور الروماني أنطونيوس بيوس.

واستمرت الإسكندرية تعاني الإهمال حتي تكونت العديد من التلال في القسم

الثرقي منها, وجف فرع الذي كان يغذي بحيرة مريوط. وعند مجئ الحملة الفرنسية الإنية 1V91 إلي مصر وصف علماؤها الإسكندرية بأنها كانت مجموعة من الأطلاد

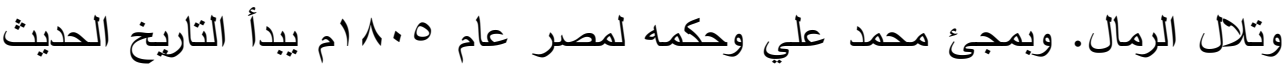


بالنسبة لمصر والإسكندرية حيث أعاد الإهنمام بهذه المدينة' . وأحتفظت الإسكندرية بشكلها القديم, والمتعارف عليه من وقت الإسكندر الأكبر حتي تولي كليوباترا , وتتقسم الموانئ الثرقية والغربية عن طريق عنق ضيق من الأرض وهي في الأصل جسر أصطناعي. منذ وقت طويل وجد طريق يربط جزيرة فاروس بالبر الرئيسي. أرسي الإسكندر بنفسه خطة المدينة العظيمة التي كانت تحمل اسمه في استق •مر وحث العرافين أن تأخذ المدينة شكل قلب. قائلاً: "أن هذا الغناء سيجعل المدينة لن تكون موارد وفيرة من تلقاء نفسها ولكن سيكون مقدم من رجال الدول التي لاحصر • لها'

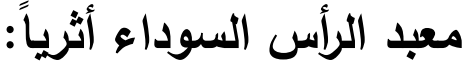

يعتبر معبد الرأس السوداء من المعابد الفربدة بين المعابد اليونانية والرومانيةَّ في مصر من حيث التخطيط , فهو يجمع بين المعبد لإقامة الطقوس والثعائر الدينية

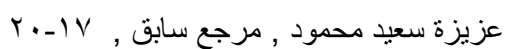

${ }^{2}$ H. Michael, Alexandria Illustrated, The American University in Cairo Press Cairo, New York, p. 3 .

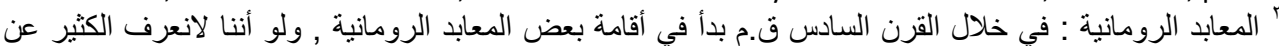

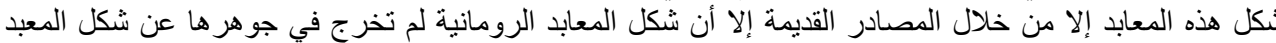

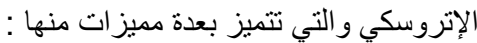

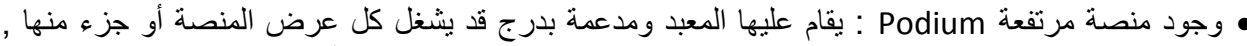

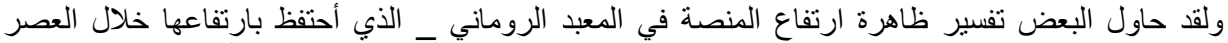

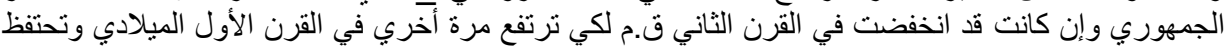

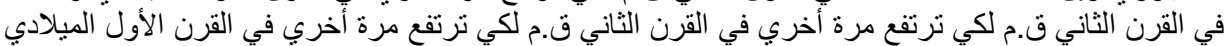

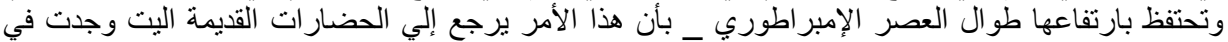

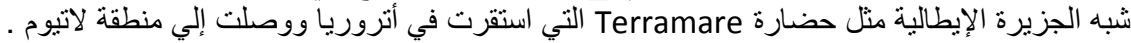

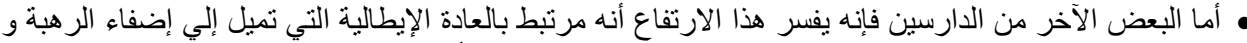

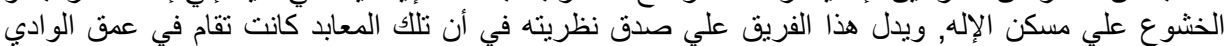

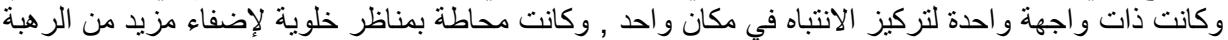
علي شكل المعبد بعكس الإغريق الذيم قربوا المسافة بين الإله والإنسان وجعلوا الآله علي شكل الإنسان وجعلة الإنها

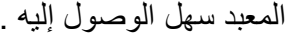

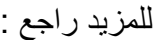

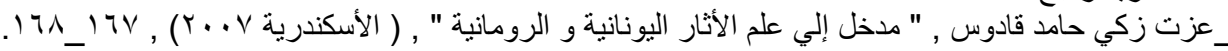

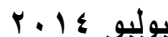
$1 \ldots 1$ العدد السابع والثلاثون 


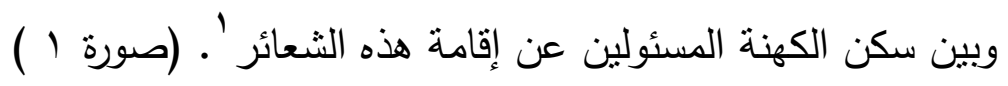

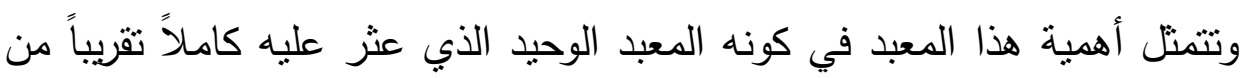
بين عشرات المعابد لكافة الآلهة الإغريقية التي تذكر النصوص الندانية القديمة إقامتها في

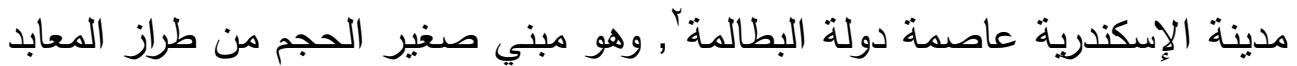
الخاصة بني علي الطراز الروماني, ويتكون من طابقين صمم الأول ليكون معبداً وصمم الثاني ليكون سكن كهنة المعبد.

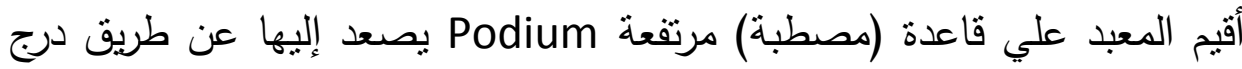

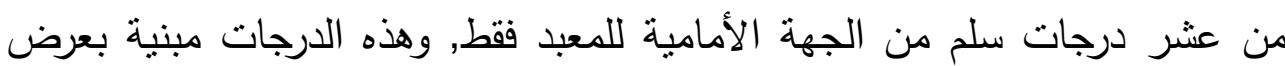

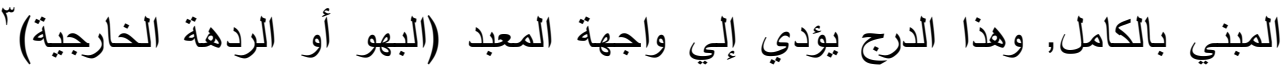
Pronaos

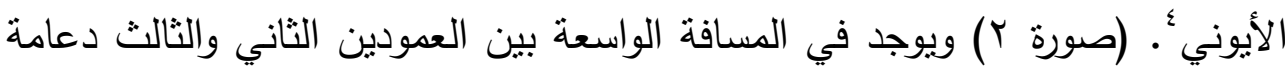

$$
\begin{aligned}
& \text { عزيزة سعيد محمود , الأسكندرية القديمة وآثار ها , صـ. } 171717 \\
& \text { للمزيد الر اجع : }
\end{aligned}
$$

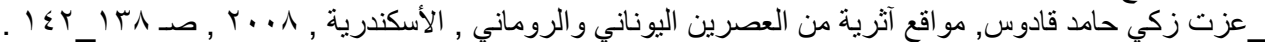

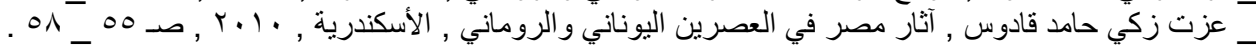

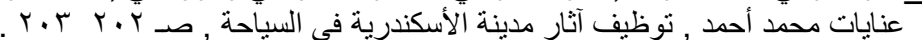

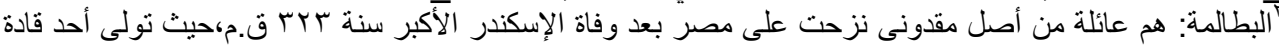

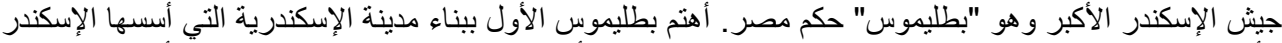

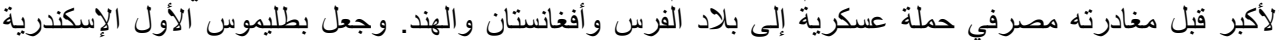

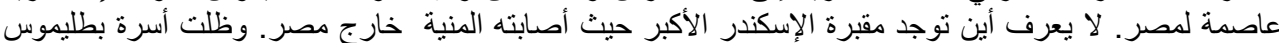

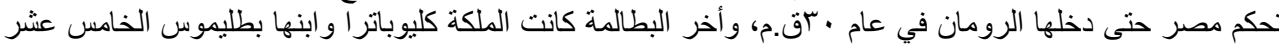

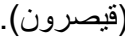
كانت العلاقة الأثرية بين البطالمة و المصريين في الآثار الباقية من تلك الفترة والتي تدل علي اهتمام الحكام البطالمة

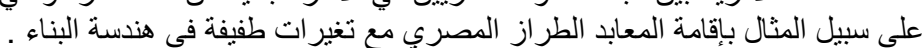

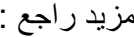

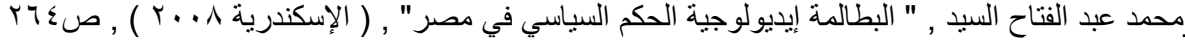
http://ar.wikipedia.org/wiki/\%D8\%A8\%D8\%B7\%D8\%A7\%D9\%84\%D9\%85\%D8\%A9

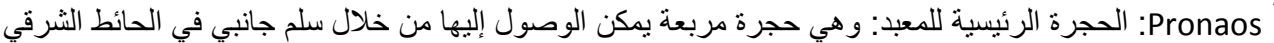

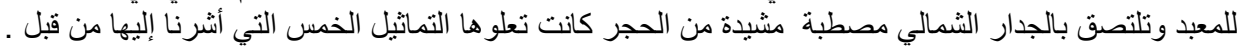

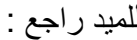

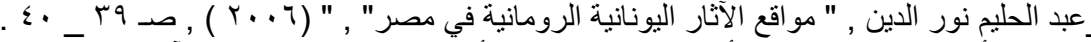

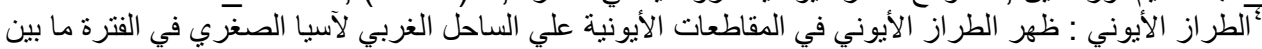

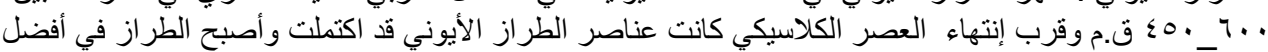

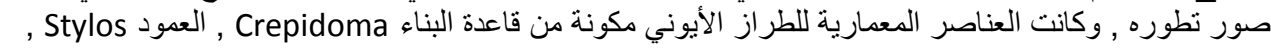
$=$

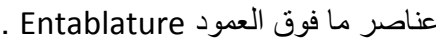
يوليو \& 1 r. 
قصيرة من الرخام الأبيض المائل إلي الزرقة, وعلي واجهتها يوجد نقش الإهداء المقدم

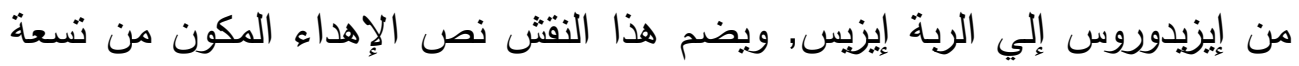
أسطر محفورة بالكتابة اليونانية وملون باللون الأحمر , وبعلو هذه الدعامة قدم منحوتة Ex voto

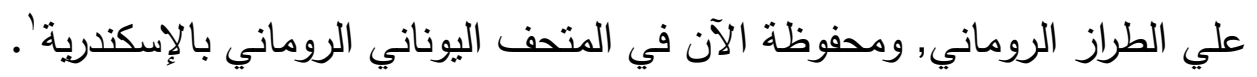
الطابق السفلي:

يبدأ الزائر بإجتياز للردهة الخارجية Pronaos وهي صالة مستطيلة الثكل ذات الأعمدة الأيونية في المدخل, ويصل الزائر إلي الحجرة الرئيسية Noas 2 وهي حجرة داخلية مربعة الثكل تمثل قدس الأقداس. وفي الحائط الشرقي لهذه الحجرة يفتح باباً يؤدي إلي سلم جانبي خارجي مستقلَ , يمكن عن طريقه الوصول إلي حجرة قدس الأقداس, ويعتقد أنه خصص لاخول الكهنة فقط. أمام الحائط الثمالي توجد مصطبة من الحجر الجيري وضع عليها خمس تماثيل من الرخام الأبيض دقيقة الصنع لآلهة المعبدّ . وهذه التماثيل رتبت من الثرق إلي الغرب علي النحو التالي: ثمثال إيزبس, ثم تمثالين لأوزوريس كانوب, ثم تمثال هرمانوبيس, ثم أخيراً تمثال لحربوقراط, هذه

The يتصل بدن العمود الأيوني بالتاج مباشرة وهذا يعني أنه لا يوجد الإمتداد الذي يسمي الرقبة التباج

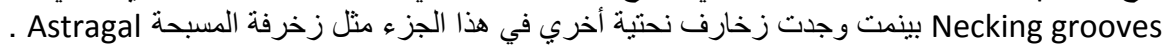

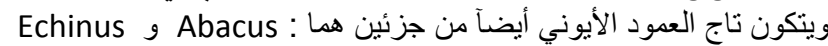

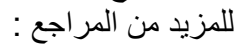

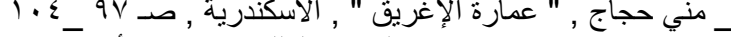

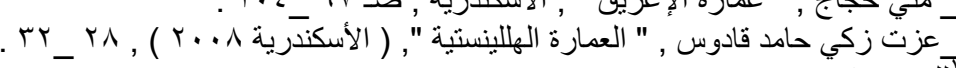

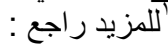

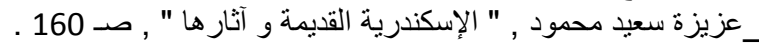

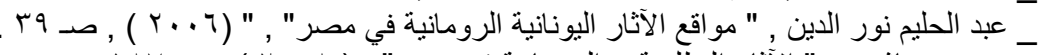

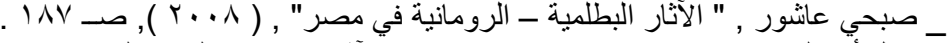

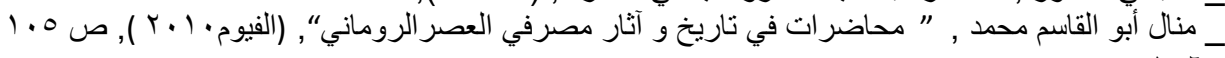
جَذا السلم الجانبي لم يتبق منه إلا الدرجتين الأولي علي مستوي أرضية الردهة الخارجية. ${ }^{3}$ H. yousryaabdel-aziz, Alexandria Historical and Archaeological Guide, Egypt, 2009, P. 32. 
التمانل موجودة الآن في المتحف اليوناني_الروماني بالإسكندرية. وأمام المصطبة

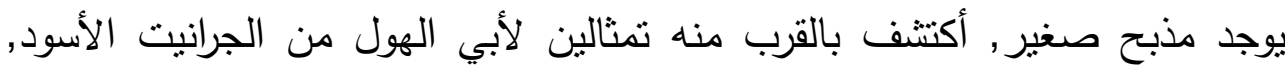

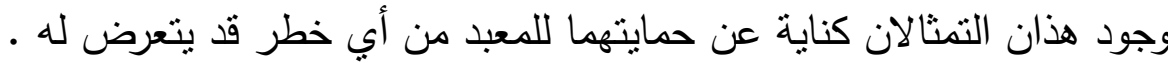

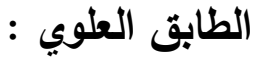

ويعد هذا الطابق في حالة جيدة بالرغم من أن الحفائر لم تكتشف بعد عن كل

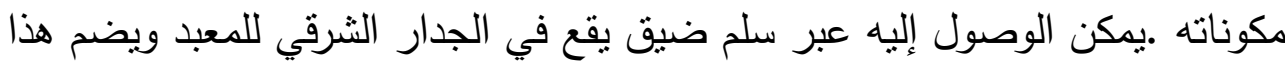

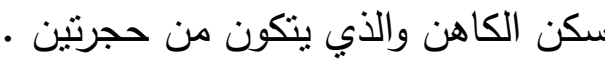
فعلي نفس محور قس الأقداس توجد حجرتان داخليتان تقعا في صف واحد مع

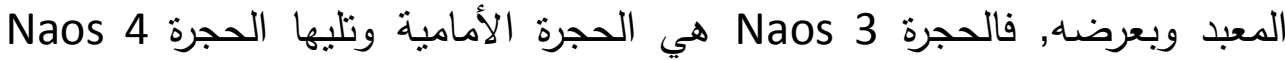
الخلفية, والحجرتان متثابهتان في طريقة البناء مع الطابق السفلي وعلي مستوي

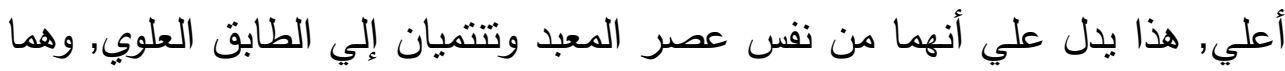

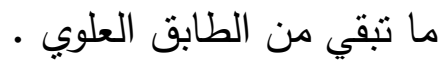

والملاحظ أن وقت إكتثاف المعبد كانت هاتان الحجرتان مهدمتان عدا الحائط الثمالي للحجرة الثالثة والحائط الثمالي والثرقي للحجرة الرابعة. والحجرة الرابعة كانت أرضيتها مغطاة في جزء منها بقطع من الرخام رصت بطريقة منتظمة , ويبدو

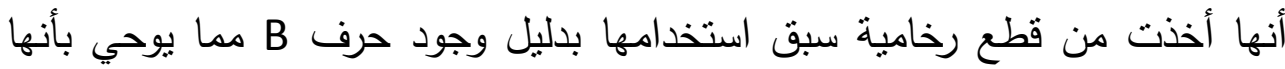

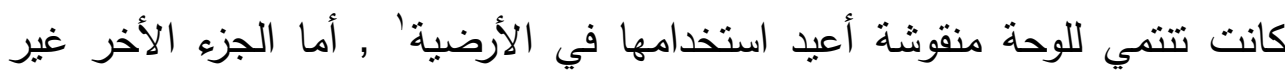

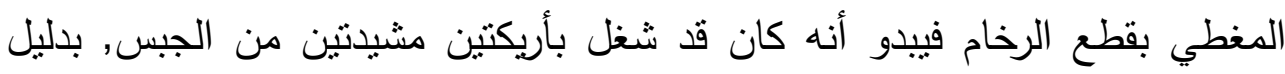

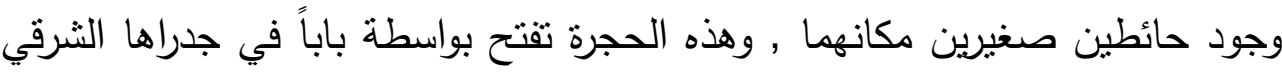
في حجرة أخري تهدمت بمرور الزمن . 


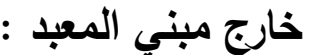

فقد كان هناك في الجهة الثمالية الثرقية عدة حجرات كانت في حالة رديئة وقت اكتثاف المعبد وتهدمت بفعل الزمن , وقد عثر في أرضية إحداها علي قناة مياة

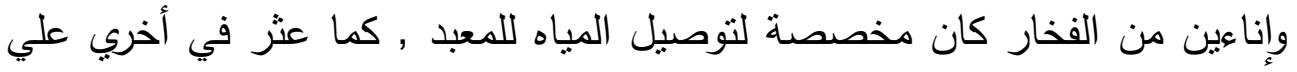

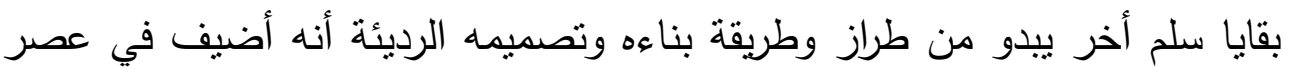

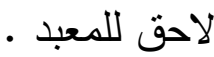

وفي الجانب الجنوبي الغربي عثر علي عدة حجرات أخري صغيرة وييدو أنها ملحقة بالمعبد, وفي الجانب الجنوبي عثر علي جزء من سور ممتد إلي جنوب الثرقي عائي وهو عبارة عن بقايا حائط عالي وعريض وييدو أنه كان يحدد مساحة المعبد. وبوجه عام فإن جدران هذا المعبد مبنية من قوالب مربعة من الحجارة التي شكلت وعان بطريقة بدائية ولا توجد أيه نقوش على جدران المعبد الداخلية والخارجية, وأن الأعمدة

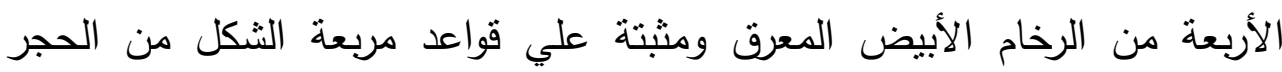

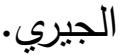

وهذا المعبد الذي أكتشف بالصدفة عام بـوام بقي مكانه مايزيد عن خمسين سنة حتي تم التفكير في نقله عام 911 ام, وتم إعداد مكان إستقبال المعبد في عام

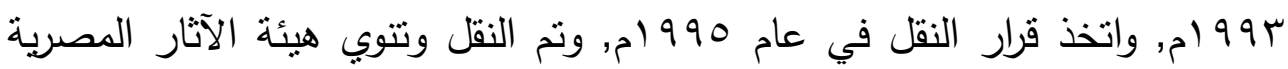
وضع نسخاً من هذه التماثيل المكتثفة في نفس أماكنها في الموقع الحديث. وجرت عملية نوثيق المعبد قبل نقله وفي نفس الوقت نهيئة الموقع الجديد لإستقبال المعبد. ورغم حرص المجلس الأعلي للآثار علي استخدام ما تبقي من الأحجار الأصلية إلا أنه نتيجة لتآكل الكثير من الأحجار فكان لابد من استخدام احجارجديدة

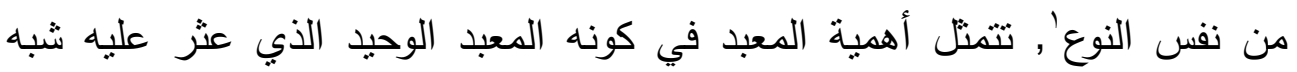


مكتمل في الإسكندرية , ييدو انه كان ملحقاً بفيلا أقامها إيزيدوروس' في نلك المنطقة

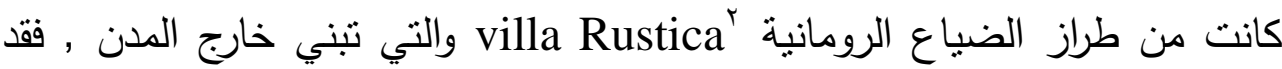
حرص صفوة الرومان والسكندريين علي بناء فيلات ريفية حول الإسكندرية القديمةج وخاصة في مناطق السيوف والرأس السوداء؛ بالقرب من مجري القناة التي تحمل المياه العذبة من فرع النيل الكانوبي إلي الإسكندرية وإلي منطقة كانوب القديمة (أبي Taposirisparva قير الحالية) خلال القرن الثاني م. , في منطقة تابوزيريس بارغاني

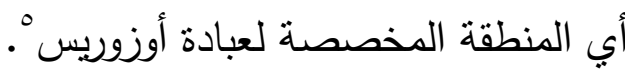
والمعبد الصغير روماني علي طراز Tetrastyle أي معبد ذو صف أعمدة أمامي, فإذا كانت الأعمدة تتقدم الردهة الأمامية للمعبد فإنه بسمي TetrastyleProstyle,

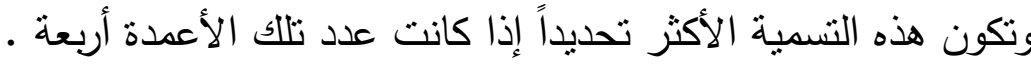

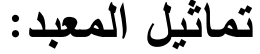

أما تماثيل آلهة هذا المعبد فهي خمس تماثيل منحوتة من الرخام الأبيض دقيقة الصنع. وهي تماثيل لإيزيس "إيزة" أقصي شرق المجموعة وأوزيريس "أوزير" والإله الائه

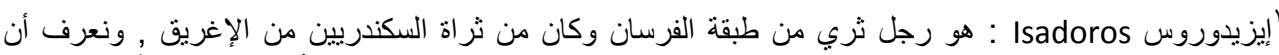

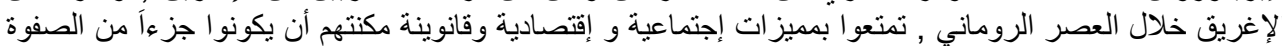
المحلية في المدينة و مصر كلها.

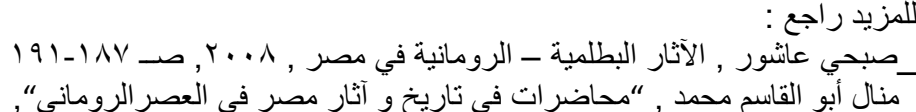

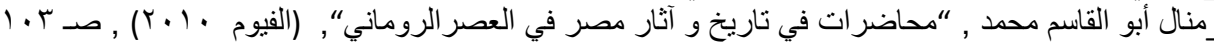

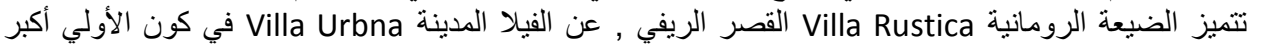
مساحة , متعددة الأجز اء و الملحقات تبني دائما خارج المها المدن , بينما الأخيرة بتعدد طو ابقها , وصغر مساحتها النسبي , ومن أهم أمثلثها فيلا لطيور بمنطقة كوم الاكة باءو بالإسكندرية.

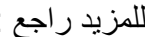

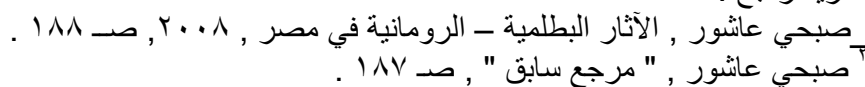

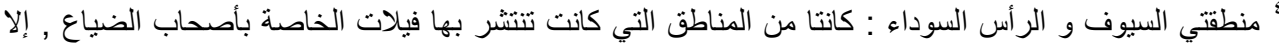
أنها تحولت الآن إلي منطقة شعبية انتشرت بها المساكن العشو ائية .

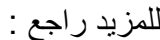

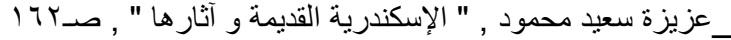

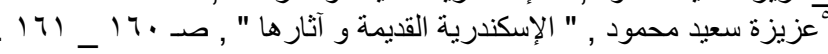
1,17 


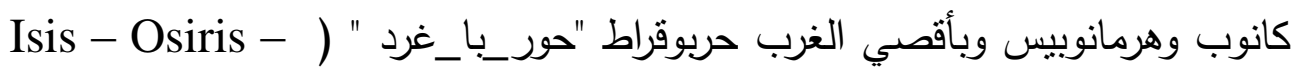
(Canope - Hermanubis - Hapocrates بالإضافة إلي تماثيل لأبي الهول 'Sphinx من الجرانيت الأسود .

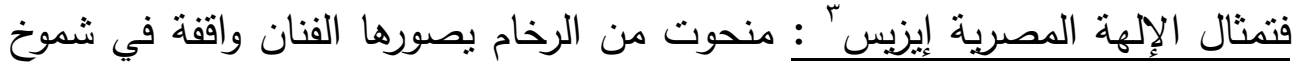

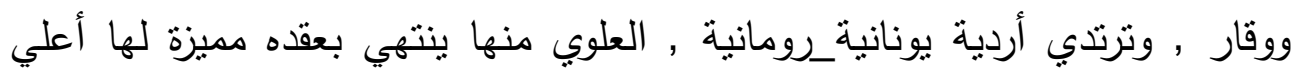

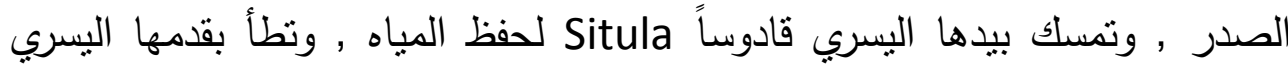

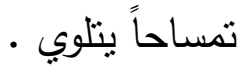

وتمثال الإلهة حربوقراط: علي هيئة صبي عادي يقف في استرجاء, وقد تهدل رداؤه

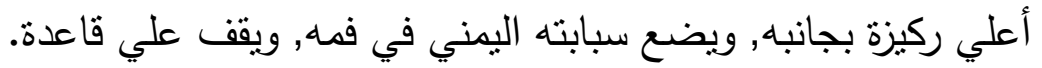

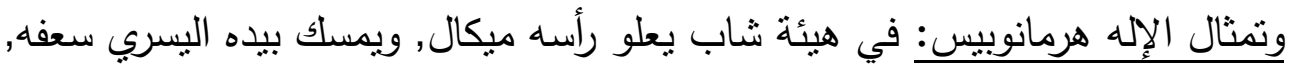

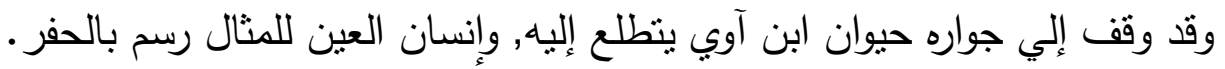

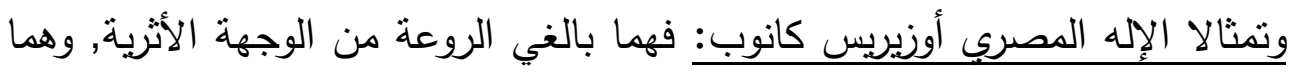

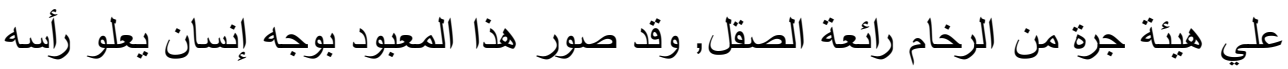

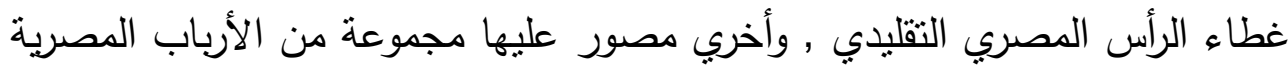

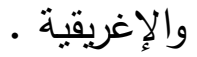

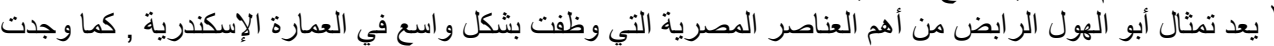

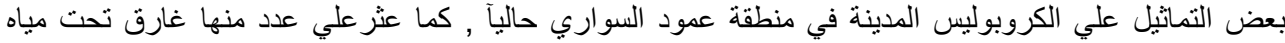

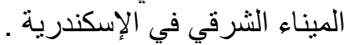

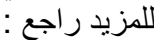

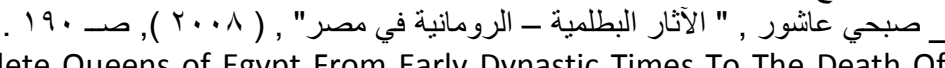
3 T. Joyce, The Complete Queens of Egypt From Early Dynastic Times To The Death Of Cleopatra , The American University In Cairo Press , 2006 , pp. 204_205 , 326_327. (For more information, please read ) :

C. Alice, Ancient Egyption Art, The American University in Cairo Press Cairo , New York, 2009, P. 280. 
ومن حجم تمثال الإلهة إيزيس بالنسبة لحجم باقي التماثيل الأخري , يتضح أن هذه

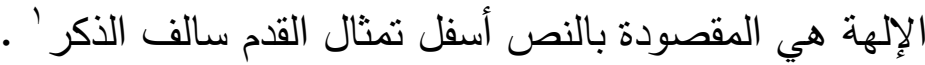

\section{معابد الإلهة إيزيس : - n}

انتشرت معابد الإلهة إيزيس' في أرجاء مناطق إنتشار عبادتها , فقد قام الحكام

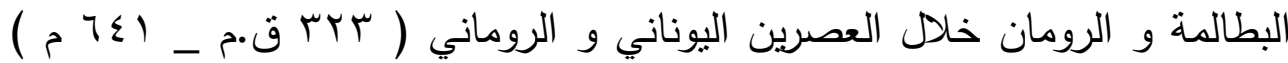
بتتيد العديد من المعابد , كهدف سياسي منواري خلف قناع ديني كأحد الطرق المختلفة للتقرب إلي المصريين وكسب ودهم • وقد تم بناء هذه المعابد بأسلوب فرعوني إلا أن تأثيرات الحضارة الإغريقية والرومانية الوافدة علي الحضارة الفرعونية , والتي عكست سماتها المعمارية والهندية والفنية إبان هذين العصرين علي الفن المصري عموماً كان منها العديد من العناصر الدخيلة علي فن العمارة في هذه المعابد . ورغم وجود العديد من المعابد التي أقيمت لعبادة الإلهة إيزيس, إلا أن الكتابات التي عثر عليها عن هذه المعابد يعتبر ضئيل إلي حد كبير كما أن ما ظهر لنا من آثارها كان كذلك أيضاً, ولكن هناك إثنارات ودلالات أثزية تمكننا من حصر بعض هذه

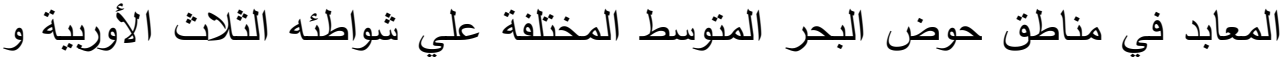

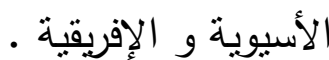

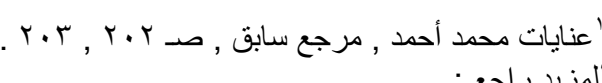

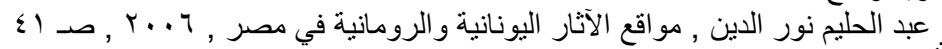

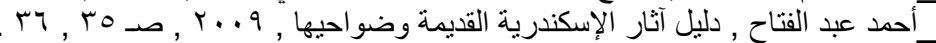

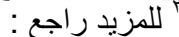

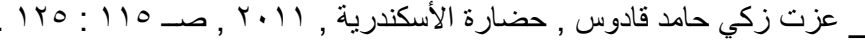

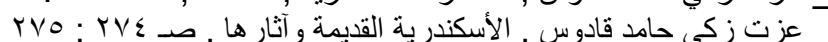

W. H. Richard ,Tha Complete Gods And Goddesses of Ancient Egypt , London , 2005 , PP. 146_148. 
فالإشارات والدلالات الآثارية تؤكد: وجود معبد للإلهة إيزيس في كل من مدينة بيلوس

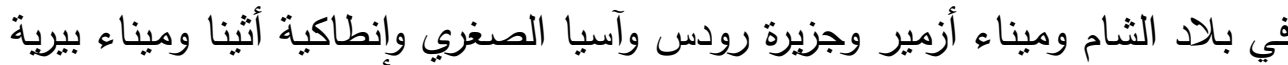

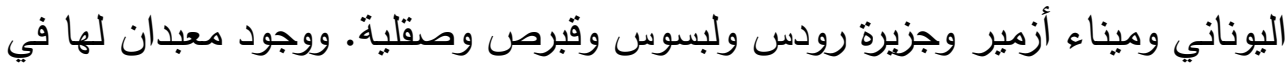
إيطاليا بميناء بوزول ومدينة بومبي, معبدان في روما فالأول بني في عهد الدكتانور سيلا والآخر في عهد الإمبراطور كاليجولا في ساحة مارس بقلب المدينة, وأقبم قصراً

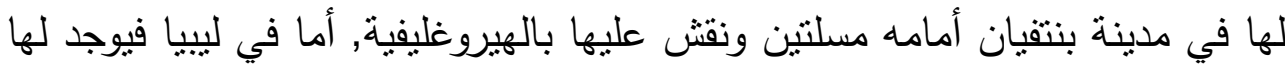
معبدان في مدينة صبراته القديمة ( صبراته حالياً ) ومدينة قوريني (ثحات حالياً) . كما تمت الإثارة إلي وجود عدة معابد للإلهة إيزيس في مصر في العصرين اليوناني والروماني في مدينة الإسكندرية , وفي إقليم طيبة في كل من أسوان ودندرة وجزيرة

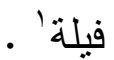

فالإثشارات والدلالات الأثرية الدالة علي وجود معابد للإلهة إيزيس في مدينة

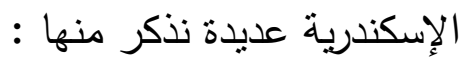

إنشارة أريانوس في كتاباته عن تأسيس مدينة الإسكندرية أنه شيد لإيزيس : عندانس

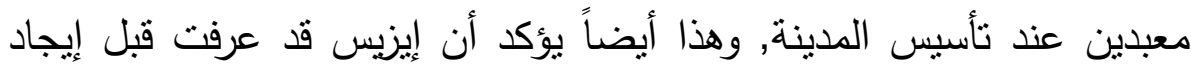
سيرابيس في الإسكندرية فقد كانت إيزيس معروفة في العالم اليوناني قبل ظهور

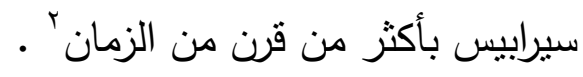

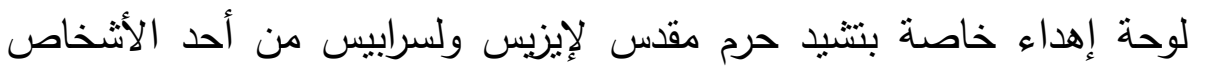
وزوجته في عصر بطلميوس الثاني عثر عليها في منطقة عبادة الثالوث

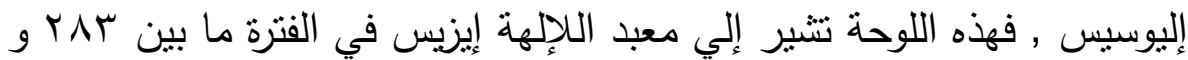

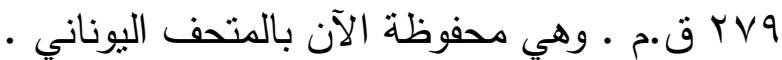

${ }^{1}$ W. H. Richard , The Complete Temples Of Ancient Egypt , Egypt , 2007 , PP. 222 2225.

- L. R. A. Schwaller De , The Temple of Karnak , Usa , 2009, pp. 24_42.

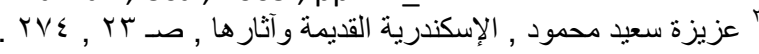

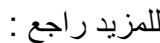

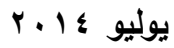

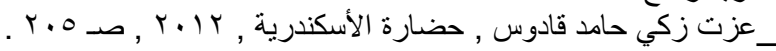
$1, .9$ العدد السابع والثلاثون 
لوحة تأسيس لمعبد إيزيس وسيرابيس أقامه بطلميوس الرابع علي طول شارع

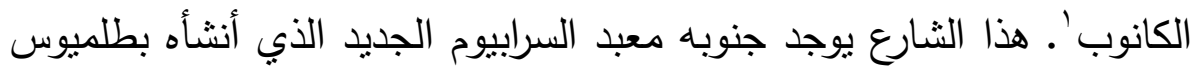
الثالث إهداء للإله سيرابيس ويأخذ الثكل المستطيل ويجاوره من الناحية الغربية معبد لإيزيس ومن الجهة الثرقية معبد لحربوقراط, أما بطلميوس الرابع فهو الذي أنشأ هيكل حربوقراط في معبد السرابيوم ذاته كما بني معبد لإيزيس وأخر لسرابيس. قد عثر علي إهداء لسرابيس في أساسات معبده كما عثر علي إهداء في هي أساسات معبد حربوقراط لكل من سيرابيس وإيزيس وحربوقراط, ولكن لم يعثر إلى الهاء علي إهداء خاص بمعبد إيزيس, لذلك لا يعرف ما إذا كان معبد إيزيس تم

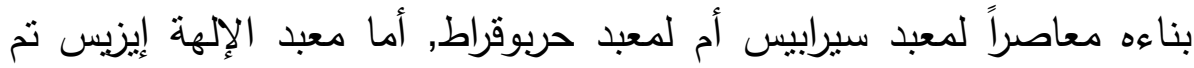

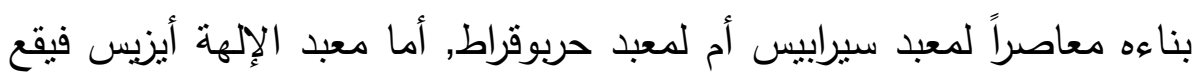

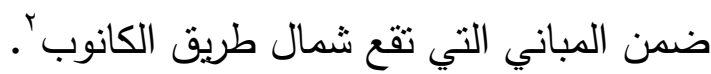

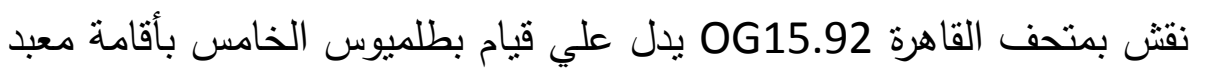
لإلإيز الربة الكبري. ا إهداء علي قطعة إسطوانية الثكل عثر عليها عام 01 ام بموقع معبد إيزيس

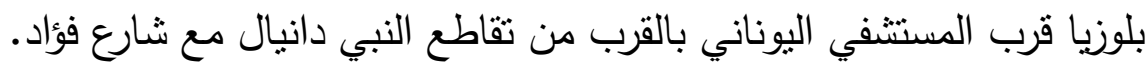

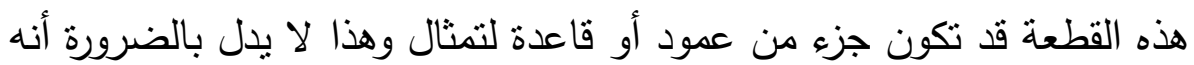
كان بذات الموقع معبد للإلهة, هذا بالإضافة إلي اتفاق إثنارات العلماء أمثال

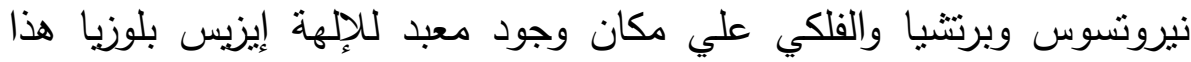

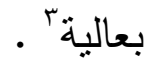


• إثارة بلوتارك (Ant.74) إلي وجود معبد لإيزيس بالقرب من مقبرة كليوباترا

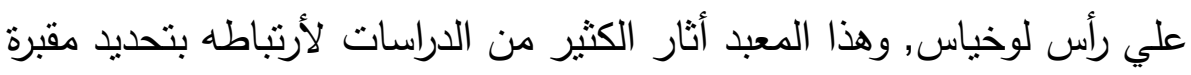

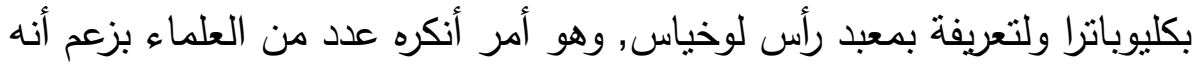
لم يكن إيزيس لقب لوخياس. إثارة نيروتسوس في خريطته إلي تحديد القصر الملكي عند نهاية رأس لوخياس لونس

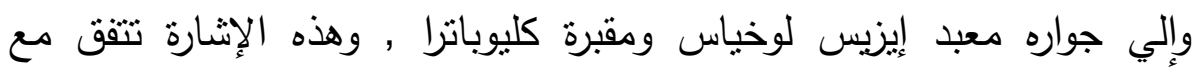
الإثارات الواردة في خرائط كل من : فون سيجلن وجوزيف بوني وبترتثيا فيما

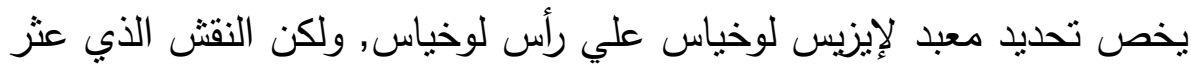

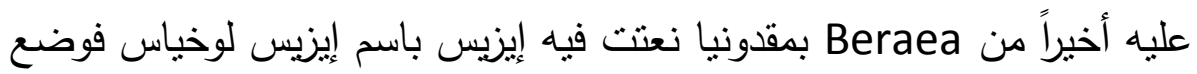

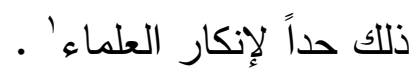
• التمثال الضخم والعدد الكبير من الأعمدة بالقرب منه وقد عثر عليهم بالقرب

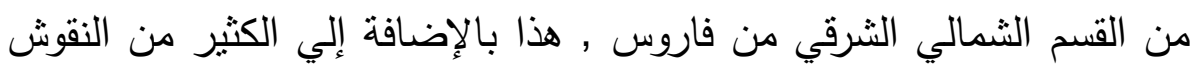
التي تضفي علي إيزيس لقب فاريا وتصور ما هكذا علي العملة الرومانية

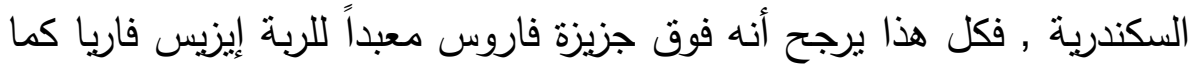

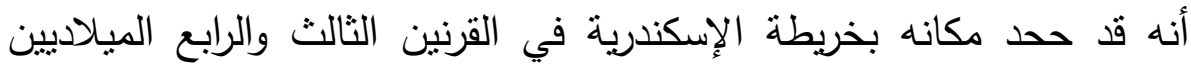
بمكان في الطرف الغربي من الجزيرة, ومن المحتمل أن يكون هذا المعبد علي في لإني غرار معبدها في بومبي ولذلك فإنه سيتم تتاول معبد بومبي بالتقصيل.

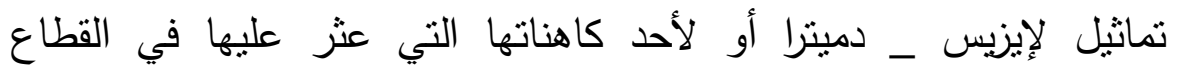
الجنوبي لمصطفي كامل باثشا توحي بوجود معبد في هذا المكان.

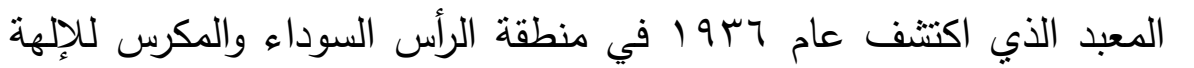
إيزيس وسمي بمعبد إيزيس بالرأس السوداء, وهذا المعبد سيتم تتاوله بالثرح. 
أما الإشارات والدلالات الدالة علي وجود معابد للإلهة إيزيس في أقليم طيية

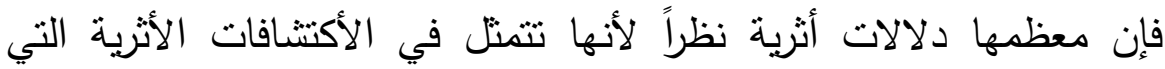
مازالت قائمة حتي الآن في أسوان ودندرة وجزيرة فيلة.

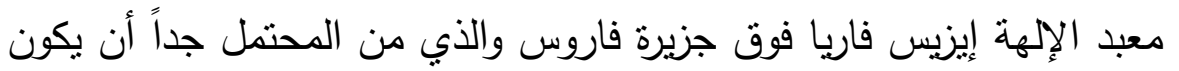
قد شيد علي غرار معبدها في بومبي'.

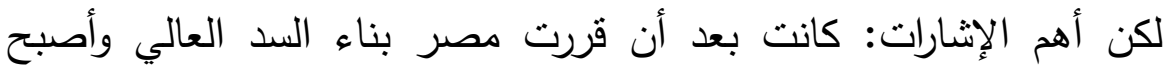

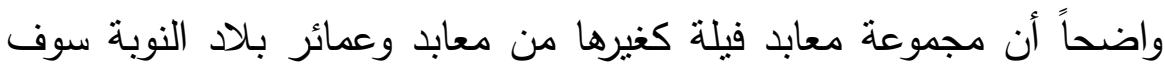

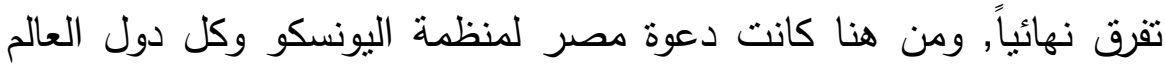
لإعداد حملة لإنقاذ آثار بلاد النوبة, وجري نقل المعابد من أماكنها إلي أماكن

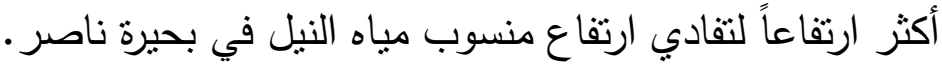
وكان من بين هذه المعابد مجموعة معابد إيزيس في جزيرة فيلة والتي تقرر بعد دراسات طويلة نقلها إلي جزيرة إجيليكا المجاورة, وهذه المعابد للإلهة

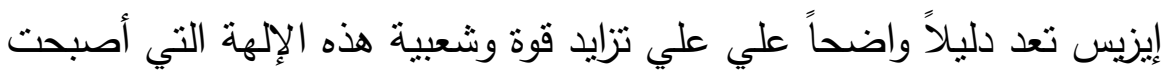
لها الهيمنة علي العقائد في العصور المتأخرة و العصرين اليوناني والروماني.

\section{Restoration}

يعتبر تزميم الآثار من العلوم الهامة التي نحتاج إليها في عصرنا هذا وذلك لإنه

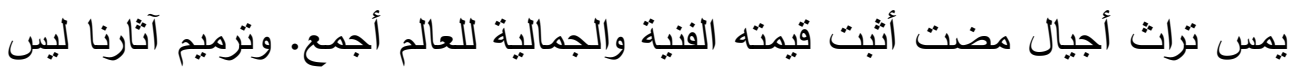

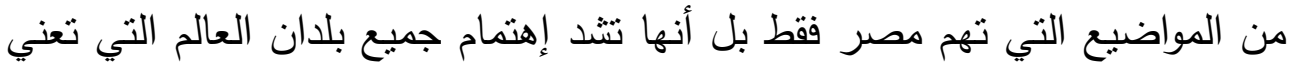
بدراسة الأجيال السابقة وتطورها. علم الترميم من العلوم الحديثة التي تبحث في كيفية الصيانة والترميم شكل(ع) والمحافظة علي التراث الحضاري, والمنمثل في حضارة وفنون القدماء, سواء كانت لعن 
فنوناً معمارية أو فنوناً تشكيلية أو فنوناً تطبيقية' أو غير ذلك من الفنون' آ. إن عملية الترميم عملية قديمة قدم التاريخ, وهي إحدي العمليات الحيوية التي تمارسها

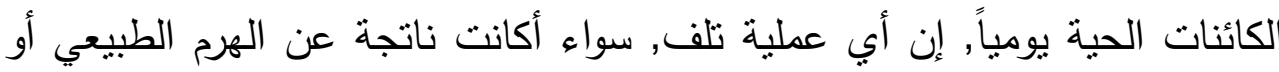

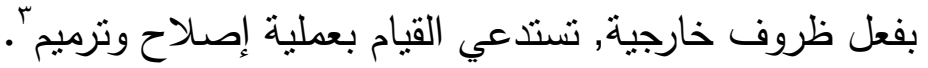
أن القرن العشرين قد شهر مولد علم جديد يخدم بطريقة مباشرة التراث الإنساني

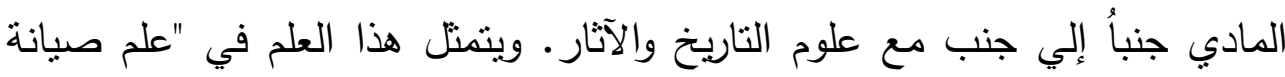
الآثار" الذي يستعين في العصر الحديث بما نوصل إليه العلماء من نتائج علمية

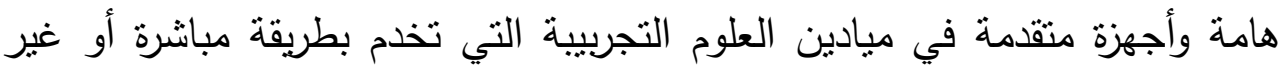
مباشرة ميادين وصيانة الآثار؛

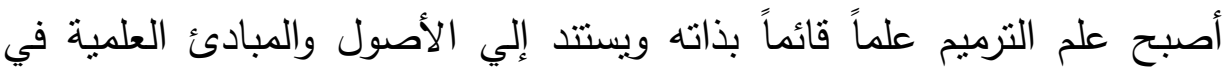
الكمياء والميكانيكا والهندة. ولهذا السبب نجد أن التخصص في ترميم الآثار يكاد

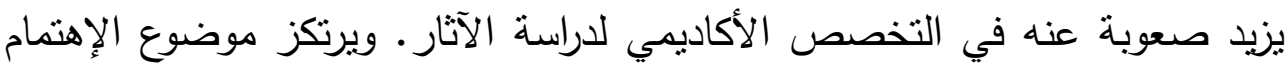

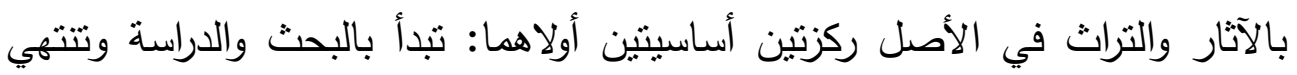

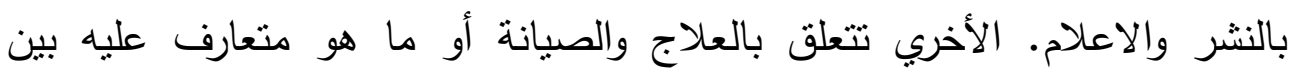

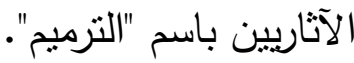
فالترميم يحتل حيزاً كبيراً وهاماً في مجال إهتمامات علم الآثار والتراث, وهو ينقسم مبدأياً إلي قسمين:

$$
\begin{aligned}
& \text { ' الفن المعماري : يشمل كل المنشأت المعمارية سواء كانت منشأة فوق أو أسفل سطح الأرض ومن أهمها : المقابر, }
\end{aligned}
$$

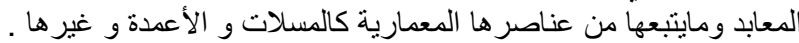

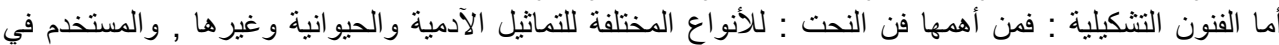

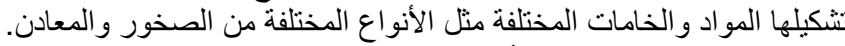

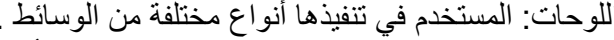

$$
\begin{aligned}
& \text { النقوش الجدارية: والمستخدم في تنفيذها الحفر البارز أو الحفر الغائر أو الألو الوان. }
\end{aligned}
$$

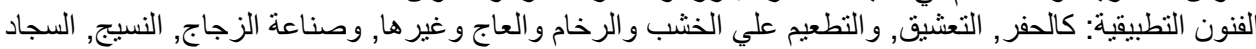

$$
\begin{aligned}
& \text { و غير ها .... }
\end{aligned}
$$

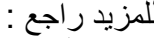

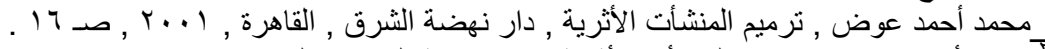

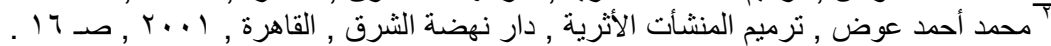

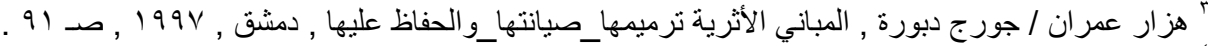

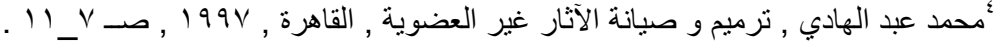


( ) نرميم الآثار الثابتة: وتشمل المباني والمشيدات بشتي أنواعها.

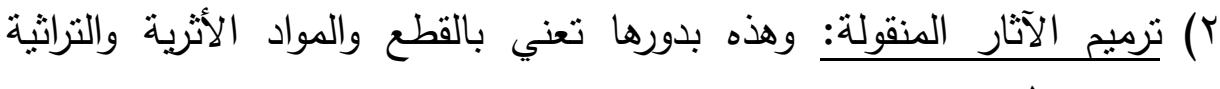

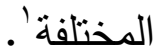

التزميم هو المحافظة علي الآثار عن طريق علاجها وصيانتها حتي لا تفقد طبيعتها الآثريه أي الحفاظ علي التراث الإنساني أكبر فتره مدكنه واستعادة شكله الأصلي بقدر الإمكان وعلم ترميم وصيانة الآتار هو علم متميز متخصص للمحافظة

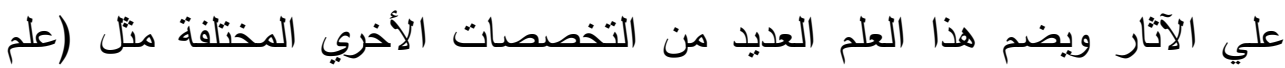

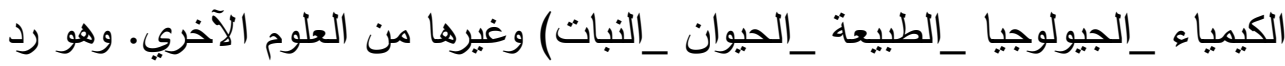

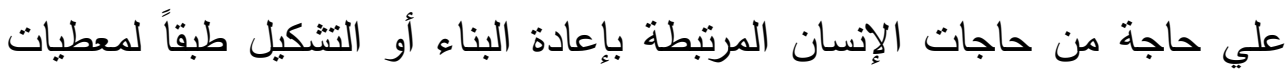

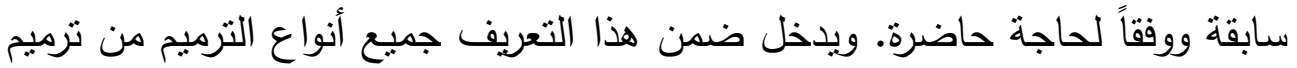

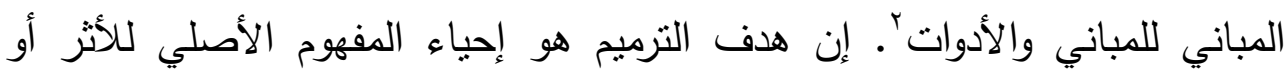

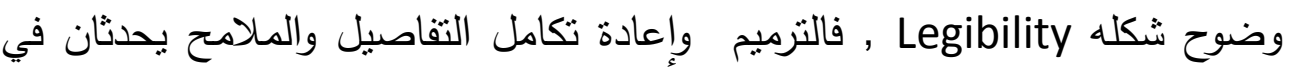
حالات كثيرة وهما يقوما علي أسس احترام المادة الأصلية والأدلة الأثرية, والتصميم وأليح

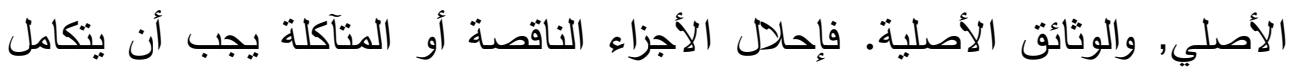

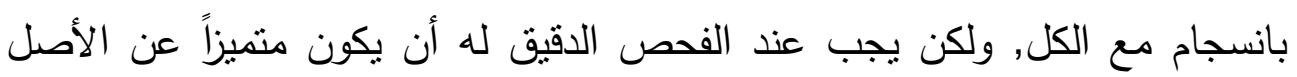

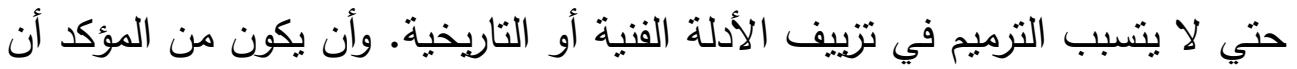

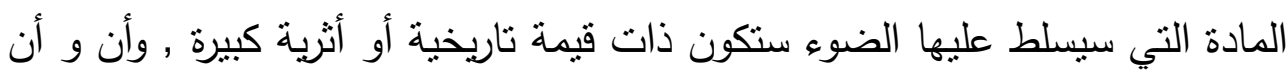

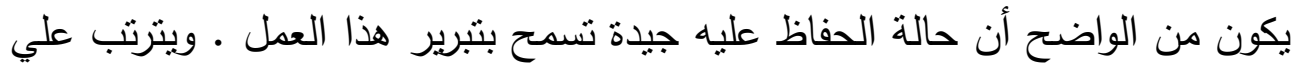

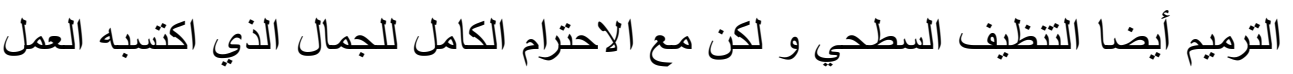

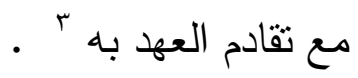

$$
\begin{aligned}
& \text { ' عبد المعز شاهين , ترميم وصيانة المباني الاثرية و التاريخية , وزارة المعارف السعودية , } 1910 \text {, , صـ } 9 \text {. }
\end{aligned}
$$

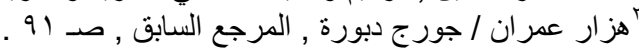
${ }^{3}$ Berned M. Feilden, the principles of Conservation in the conference of ( Conservation of historic Stone Building) , 1982 , p. 29.

يوليو ؛ 
فلسفة الترميم المعماري وتطورها : Philosophy of Architectural Restoration and Restoration and its Evolution

تعرضت المفاهيم النظرية لترميم الآثار إلي تعديلات واضحة خلال العقود الأخيرة,

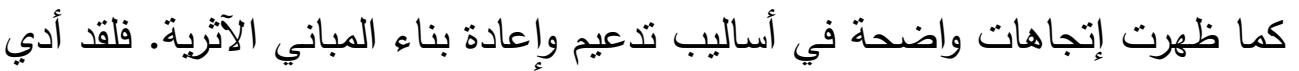

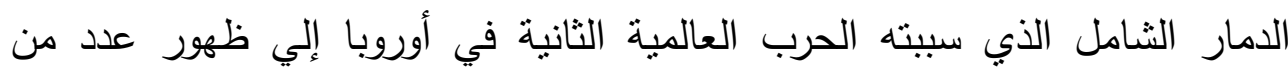
المشكلات الجديدة التي مست المفاهيم الأساسية للترميم, فبالإضافة إلي المسائل التقليدية مثل كيفية التخلص من الإضافات وتحديد التاريخ الأمنل للترميم, وإستعمال

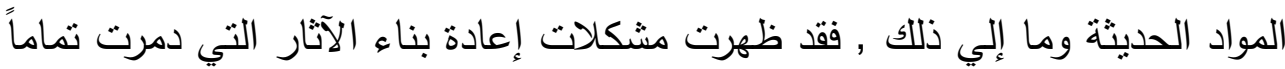

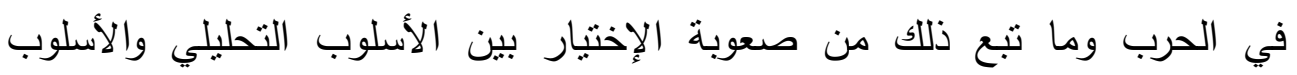
التكاملي. يمكن تلخيص سياسة وفلسفة الترميم في المراحل التالية:

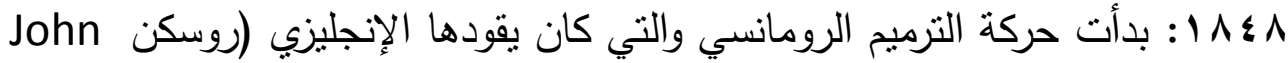

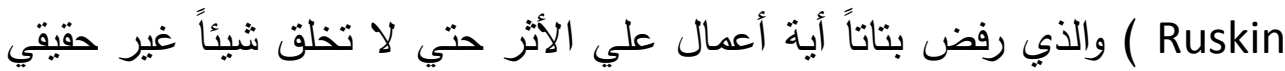

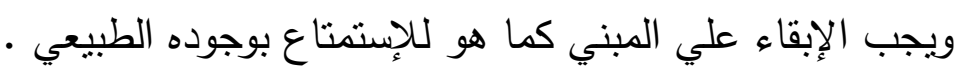

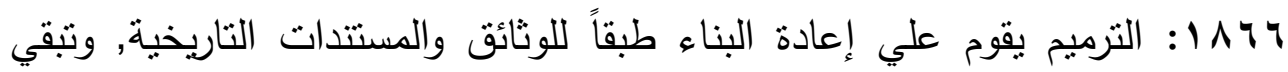
الأعمال مجرد أنكال ممسوخة من الآتار وكان يقود هذا الإتجاه الفرنسي (فيوليت لي دوك Violet-le-Duc) بنظريته التي تقوم علي أن ترميم مبني هو إرجاعه إلي حالته هئه المثالية والتي يمكن إلا يكون وصل إليها أبداً.

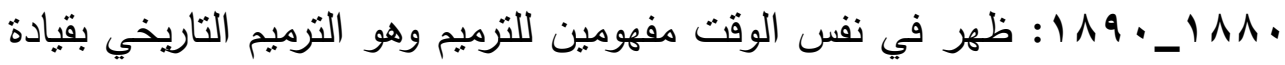

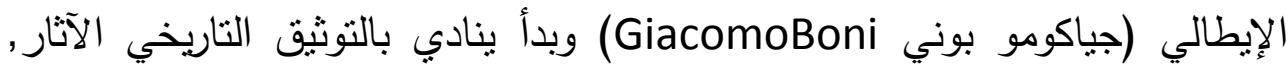
والآخر الإيطالي (كاميللوبوبتي Gamillo Boito) والذي يقوم علي المعرفة التاريخية

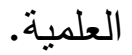




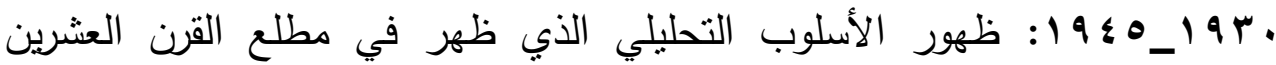
وتبلور في مؤتمر أثثنا عام اسوا اوتطور في الثلاثنينات إلي نظرية علمية الآثار

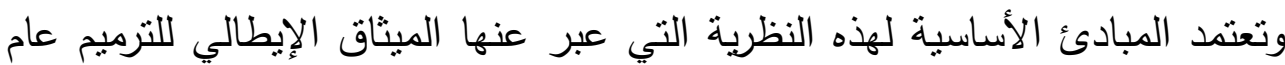

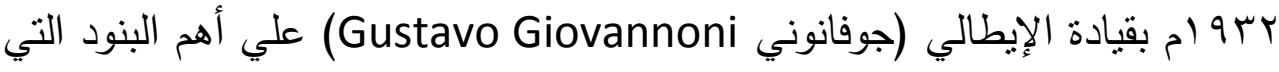

$$
\text { تبلورت في: }
$$

- بسمح فقط بالأعمال التكميلية البسيطة الني لاغني عنها لسلامة الأثر • - الحفاظ علي فترات إنشاء الأثر , وعدم تتشويهه بالإضافات الخاطئة . - إعادة الوظيفة الفنية للأثر · ل

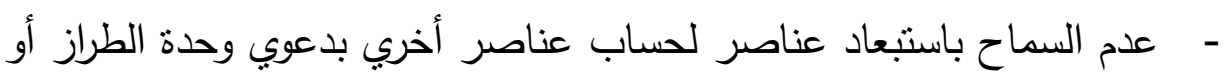

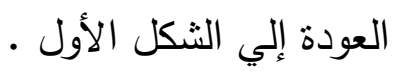

0؛ 19 : ظهور نظريات الترميم النقدي (روبرتو باني Roberto Pane) ونظرية ترميم الوحدة الكامنة (براندي Brandi) وكذلك نظرية الترميم المعرفي (نيقولا برونكو). والسمة الواضحة المميزة لنظرية التزميم النقدي والتي وضعت خصائصها

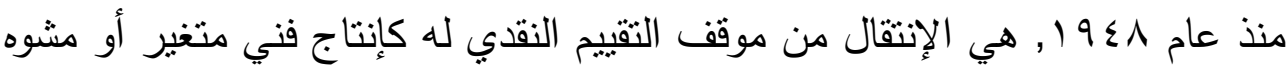
بما يتبع ذلك من إصلاحات عن طريق التنخل الإبداعي للفنان أو للمعماري, ويقول

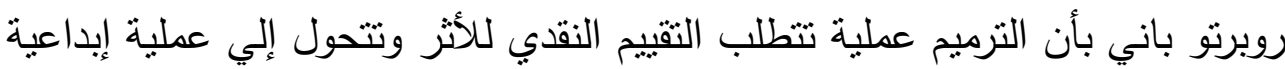

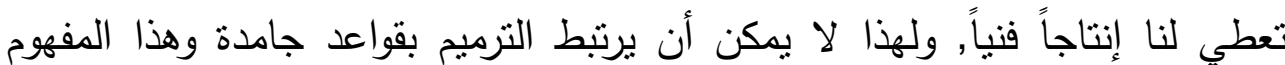

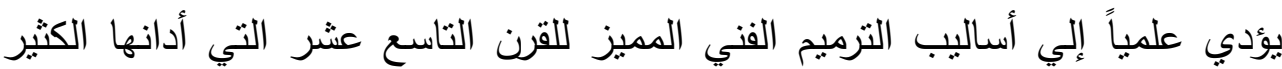
من العلماء.

؛ 9 1: صدور معاهدة حماية التراث الحضاري في حالة العدوان والتني أصدرتها اليونسكو في § ا مايو ع 190 ونص أول قرار فيها عن أمله في تسابق أعضاء الأمم المتحدة في حالة الأعنداء العسكري القيام بتجهيز القرارت اللازمة للنأكد من تطبيق شروط المعاهدة وذلك بواسطة القوة العسكرية التي تتحمل جزءاً من هذا التطبيق,

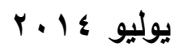


ونصت أيضاً أنه في حالة وقوع إعتداء عسكري أو حالة قرب وقوعه يتم التأكيد علي التراث الحضاري الموجود بالبلد الأخري وأن يكون معروفاً , ويتم حمايته بواسطة القوة فئماء

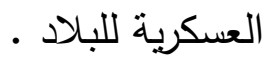

ـ 9 1 1: قانون الترميم الدولي_ميثاق فينسيا للترميح_وجه النظر إلي أهمية الإعتتاء

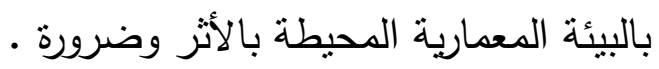

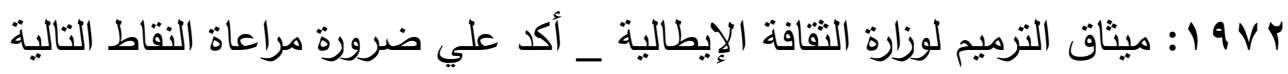

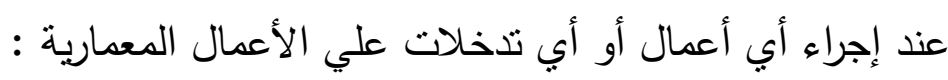

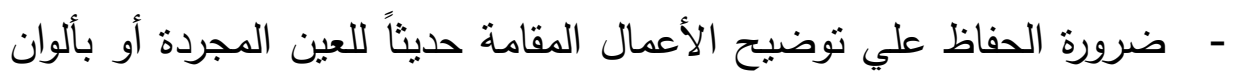
محايدة وعلي مستوي مختلف مع العمل الأصلي. - - رفض إعادة البناء ولكن إعادة التكوين لمكونات المبني الباقية بمواد صلبة البعائ

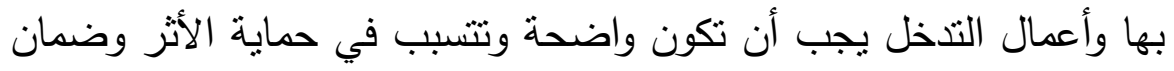

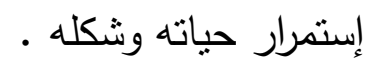
- - أي إستخدام لمواد في الترميم يجب أن تضمن في المستقبل عدم إستحالة أي

$$
\text { - مهديد مفلات أخري لإجراءات الصيانة والترميم. }
$$

•191: ميثاق لاهور الخاص بحماية التراث الإسلامي, والي نص علي أنه أثناء

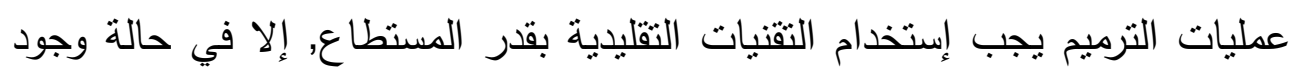
ضرورة قصوي فيمكن إستبدالها بالتقنيات الحديثة. ؟ 99 1 1: إعلان ناراً للأصالة باليابان The Nara Document On Authenticity المجلس الدولي للحفاظ علي المباني والمناطق الآثرية Icomos ولقد ركزت وثيقة ناراً علي أهمية التمسك بالإتفاقات والمواثيق الدولية الخاصة للمجتمع راني و و احترامها والتأكد

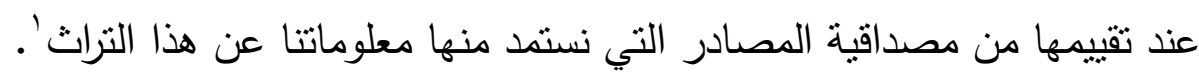

${ }^{1} J u k k a$,jokilehto, Conservation principles and their Theoretical Background, Rome, 1988, p. 267.

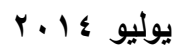

$1.1 \mathrm{~V}$

العدد السابع والثلاثون 
اكتسب موقع الإسكندرية أهمية كبيرة فى العصور الفرعونية وخاصة فى عصر الدولة الحديثة، حيث أنها تقع على قطعة من اليابسة تكونت فى الأزمنة

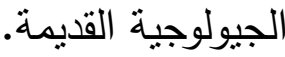

استرعى انتباه الإسكندر الأكبر بقعة من اليابسة تفصل البحر المتوسط عن بحيرة مريوط ففكر فى تللك البقعة ذات المواصفات التى تصلح لإنثاء مدينة تحقق الإنق

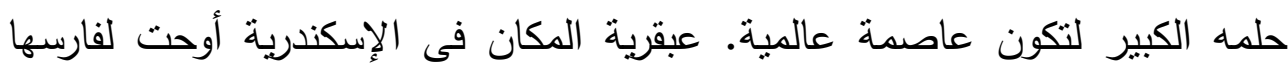

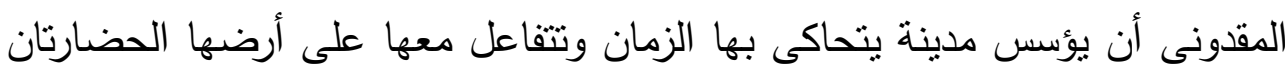
الإغريقية والمصرية.

اختار المهندس "دينوقراطيس" النمط الهيبودامي لتخطيط هذه المدينة وتحدث

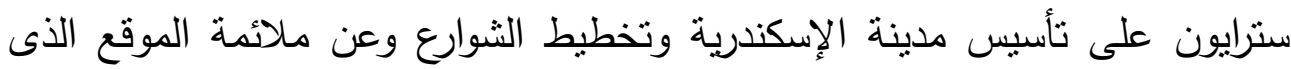

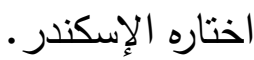

يعتبر معبد الرأس السوداء بالإسكندرية المعبد الرومانى الوحيد الذى عثر

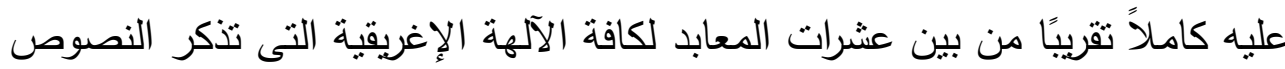
القديمة إقامتها فى مدينة الإسكندرية عاصمة دولة البطالمة. هذا المعبد خصص للآلهة إيزيس إهداء من "إيزيدوروس" عرفانًا لها لأنها حفظته من سقطة مميتة. وقد انتشرت معابد الآلهة إيزيس فى أرجاء المناطق لانتشار عبادتها. ومن بعد ذللك يعتبر ترميم الآثار من العلوم الهامة التى نحتاج إليها فى

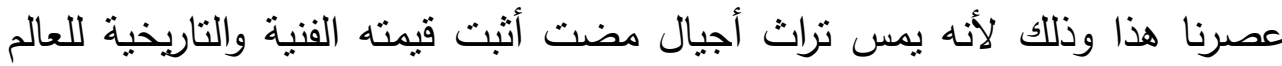
أجمع. 

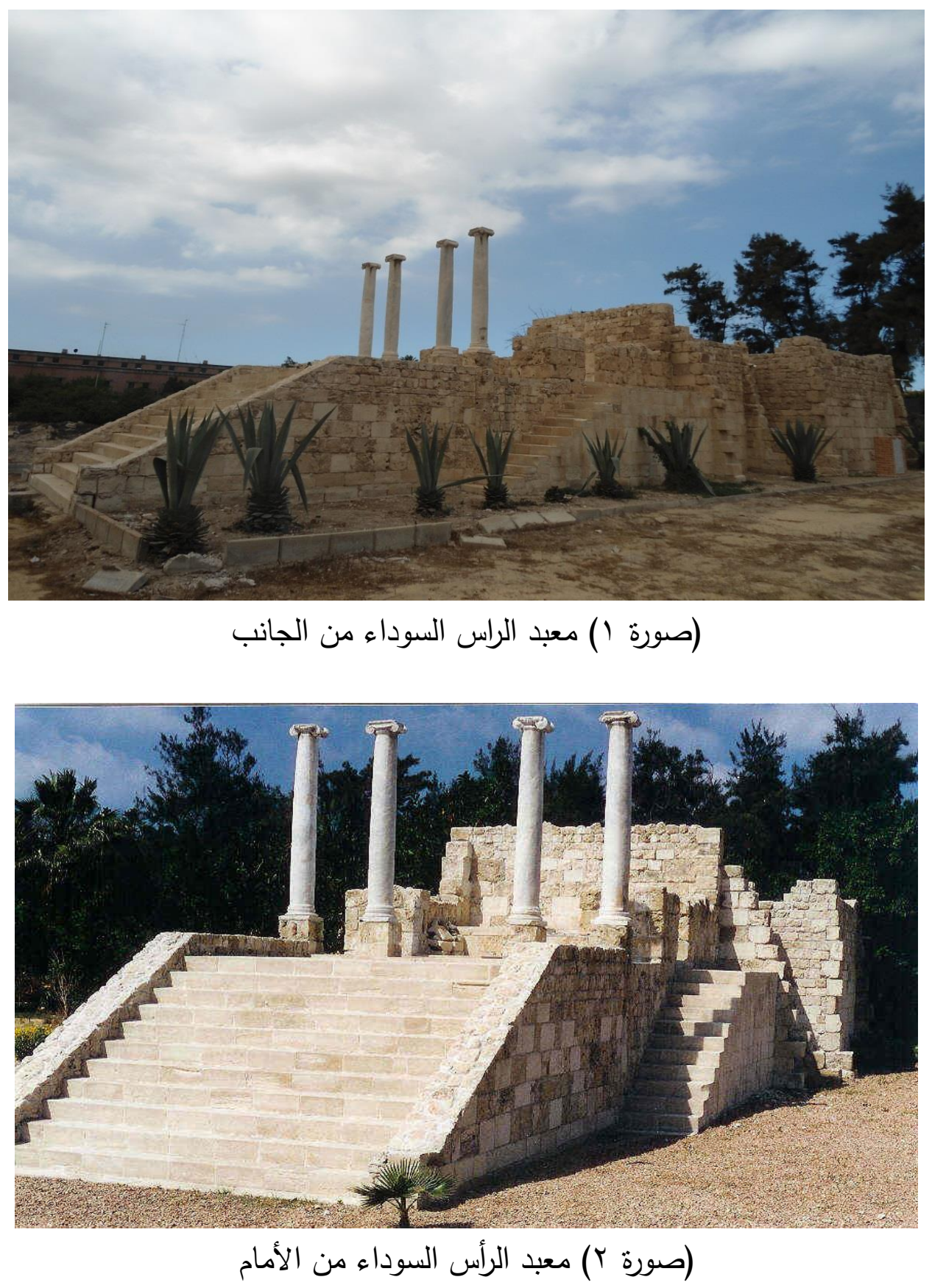

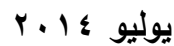

1.19

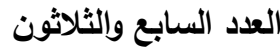




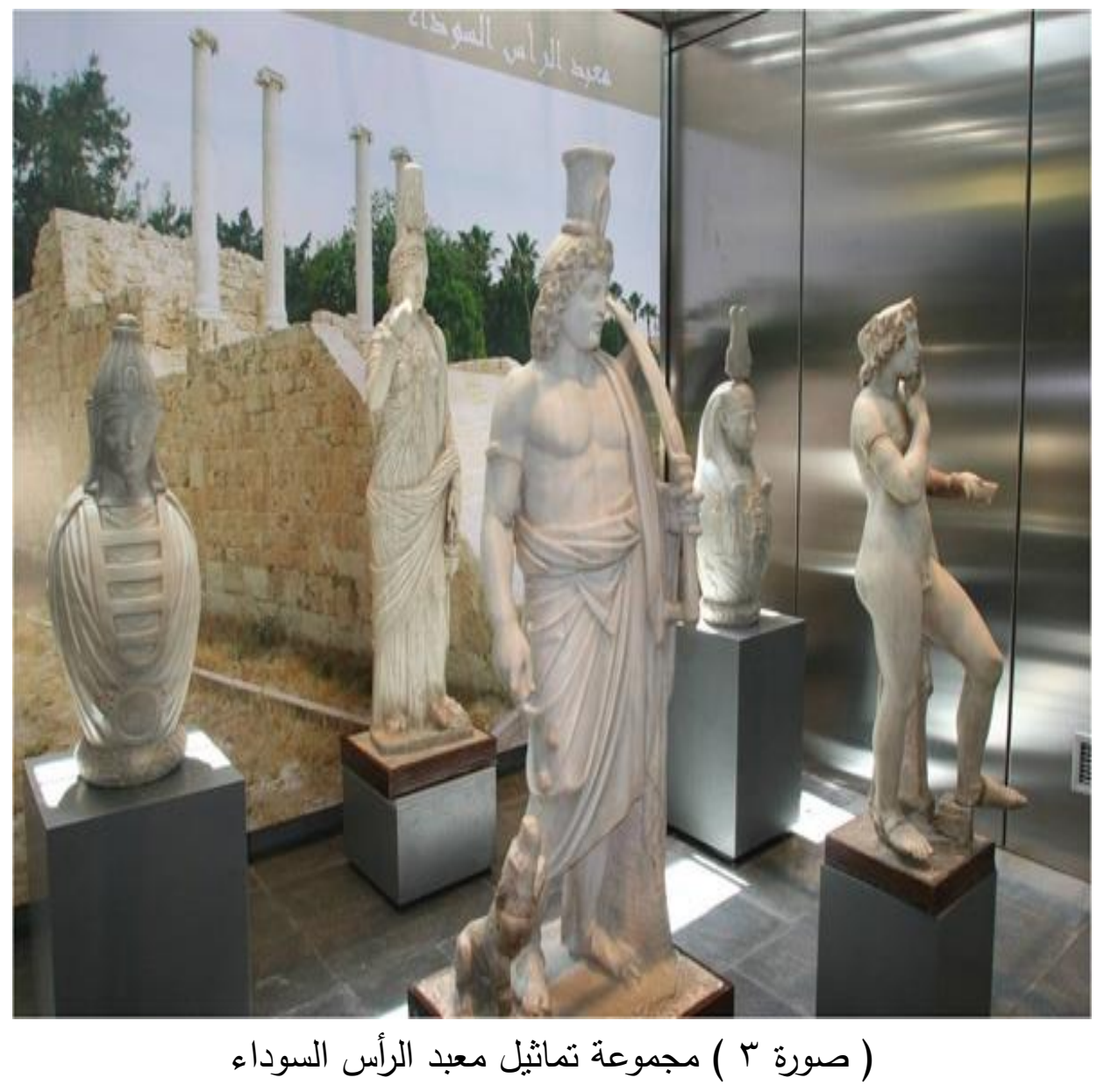




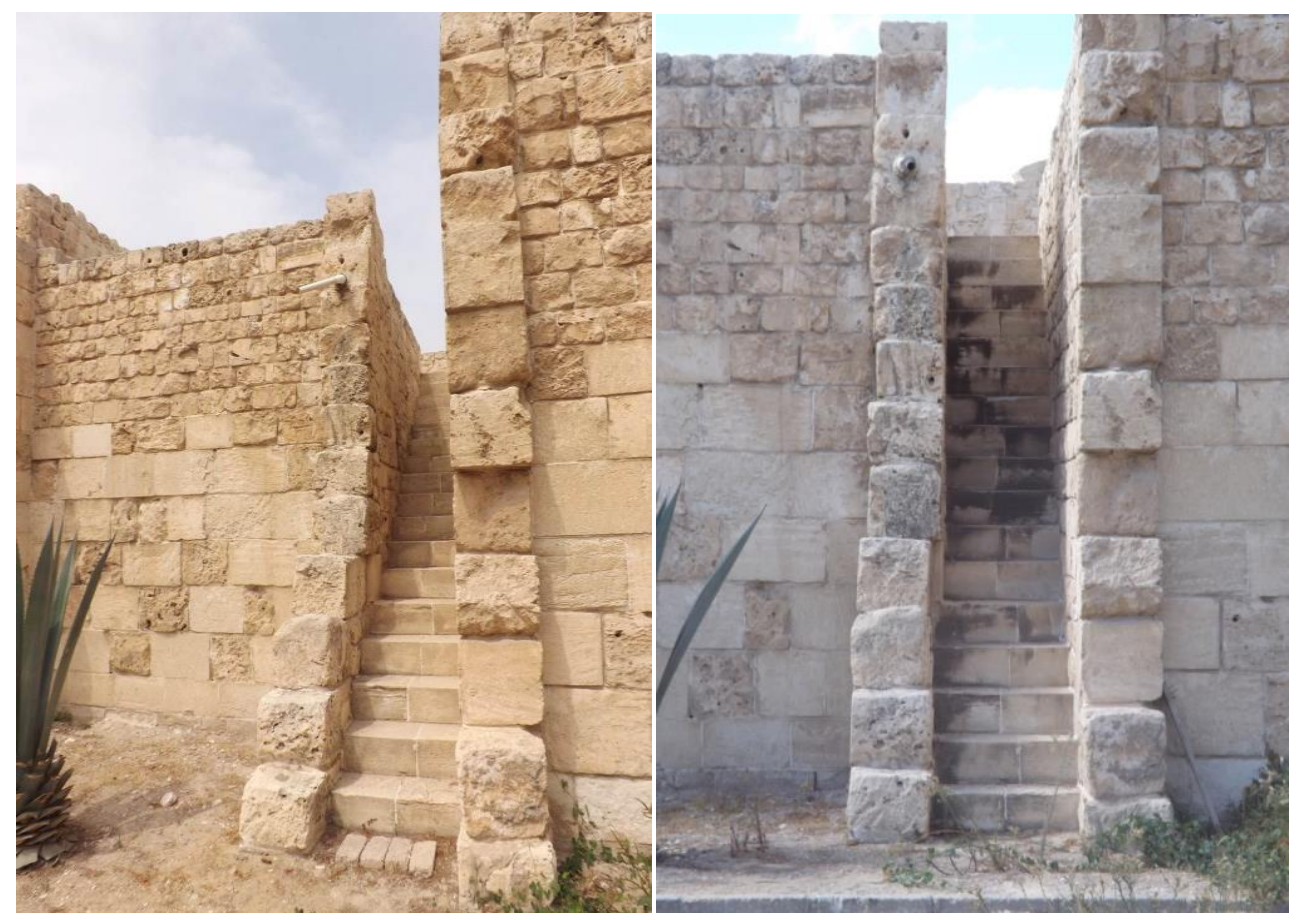

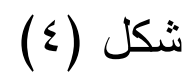

سلم المعبد قبل وبعد الترميم مع استخدام المواد الخاصة بعملية الترميم 


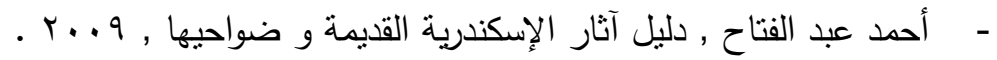

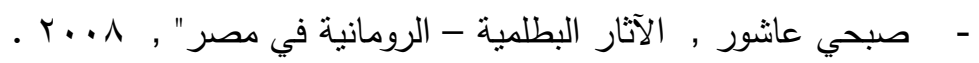

- - عزيزة سعيد محمود , الإسكندرية القديمة و آثارها , الإنكندرية.

- عزت زكي حامد قادوس, مواقع أثرية من العصرين اليوناني والروماني, الإنكندرية,

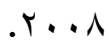

- عزت زكي حامد قادوس, آثار مصر في العصرين اليوناني والروماني, الإسكندرية,

.r. . .

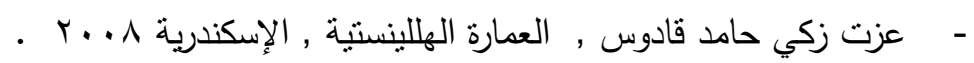

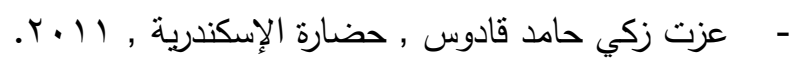

- عنايات محمد أحمد , توظيف آثار مدينة الإسكندرية في السياحة.

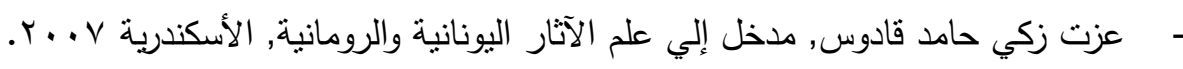

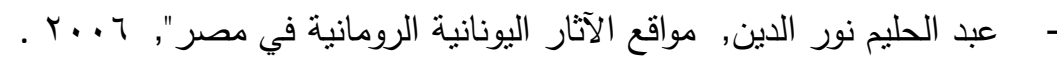

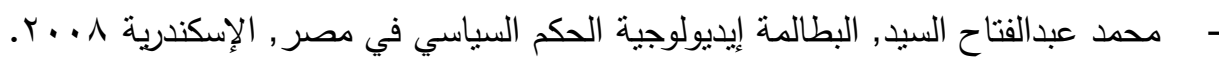

- مني حجاج , "عمارة الإغريق الإنكندرية.

- منال أبو القاسم محمد , " " محاضرات في تاريخ و آثار مصر في العصر الروماني,

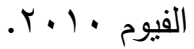

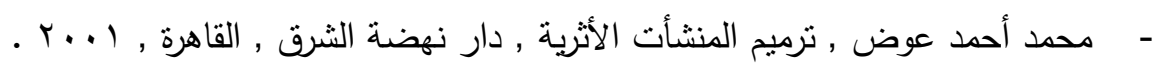

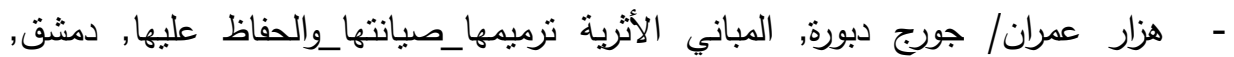

\section{المراجع الأجنبية : - أ}

- Berned M. Feilden , the principles of Conservation in the conference of ( Conservation of historic Stone Building) , 1982.

- Bernand , A. , Alexandrie la Grande , Arthaud , 1966.

- C. Alice, Ancient Egyption Art, The American University in Cairo Press Cairo, New York , 2009 
- .H. yousryaabdel-aziz, Alexandria Historical and Archaeological

Guide , Egypt , 2009 .

- Jukka, jokilehto, Conservation principles and their Theoretical Background, Rome, 1988 .

- H. Michael, Alexandria Illustrated, The American University in Cairo Press Cairo, New York.

- L. R. A. Schwaller De , The Temple of Karnak, Usa , 2009.

- N. A. Mervit, Alexandria and others centers of Thought in Ancient Egypt, Alexandria , 2011.

- W. H. Richard ,Tha Complete Gods And Goddesses of Ancient Egypt, London , 2005.

- $\quad$ T. Joyce, The Complete Queens of Egypt From Early Dynastic Times To The Death Of Cleopatra , The American University In Cairo Press , 2006.

- W. H. Richard, The Complete Temples Of Ancient Egypt, Egypt , 2007. 